\title{
Statistical downscaling and projection of future temperature and precipitation change in middle catchment of Sutlej River Basin, India
}

\author{
Dharmaveer Singh ${ }^{1}$, Sanjay K Jain ${ }^{2}$ and R D Gupta ${ }^{1,3, *}$ \\ ${ }^{1}$ GIS Cell, Motilal Nehru National Institute of Technology, Allahabad 211 004, India. \\ ${ }^{2}$ Water Resources Systems Division, National Institute of Hydrology, Roorkee 247667 , India. \\ ${ }^{3}$ Department of Civil Engineering, Motilal Nehru National Institute of Technology, Allahabad 211 004, India. \\ ${ }^{*}$ Corresponding author.e-mail: gupta.rdg@gmail.com
}

Ensembles of two Global Climate Models (GCMs), CGCM3 and HadCM3, are used to project future maximum temperature $\left(T_{\mathrm{Max}}\right)$, minimum temperature $\left(T_{\mathrm{Min}}\right)$ and precipitation in a part of Sutlej River Basin, northwestern Himalayan region, India. Large scale atmospheric variables of CGCM3 and HadCM3 under different emission scenarios and the National Centre for Environmental Prediction/National Centre for Atmospheric Research reanalysis datasets are downscaled using Statistical Downscaling Model (SDSM). Variability and changes in $T_{\mathrm{Max}}, T_{\mathrm{Min}}$ and precipitation under scenarios A1B and A2 of CGCM3 model and A2 and B2 of HadCM3 model are presented for future periods: 2020s, 2050s and 2080s. The study reveals rise in annual average $T_{\mathrm{Max}}, T_{\mathrm{Min}}$ and precipitation under scenarios $\mathrm{A} 1 \mathrm{~B}$ and $\mathrm{A} 2$ for CGCM3 model as well as under A2 and B2 scenarios for HadCM3 model in 2020s, 2050s and 2080s. Increase in mean monthly $T_{\text {Min }}$ is also observed for all months of the year under all scenarios of both the models. This is followed by decrease in $T_{\text {Max }}$ during June, July August and September. However, the model projects rise in precipitation in months of July, August and September under A1B and A2 scenarios of CGCM3 model and A2 and B2 of HadCM3 model for future periods.

\section{Introduction}

The past and future information about patterns and variability of surface climate such as temperature and precipitation are used to evaluate and model, impact of climate change on different earth surface processes at macro and micro scales (Marshall et al. 2007; Anandhi et al. 2008). Investigating how change in climate will alter future temperature and precipitation along with their spatial and temporal variability is an area of active research (Basistha et al. 2009). An appropriate assessment of likely future temperature and precipitation is done under different climate scenarios. Climate scenarios which refer to plausible future climate are a time series of synthetic weather data (Lapp et al. 2009). The procedures for development of climate scenarios have been discussed in literature (Robinson and Finkelstein 1991; Easterling 1999).

The projection of global climate change on continental scale under different emission scenarios of Green House Gases (GHG) is done with the aid of Global Climate Models (GCMs), sometimes also referred as General Circulation Models (Mahmood and Babel 2013). GCMs inherited disadvantages of having a very coarse spatial resolution (around 200-400 km) and their failure in simulating subgrid scale features and physical dynamics (Xu 1999;

Keywords. Downscaling; temperature; precipitation; SDSM; CGCM3; HadCM3. 
Yang et al. 2010). The decrease in spatial accuracy of GCMs simulated climate variables occurs from continental to local scale. This restricts the direct applications of GCM's outputs in regional climate change impact studies. As a result, techniques usually known as 'downscaling' have been invented for narrowing the gap between the scale of GCMs and required resolution for impact assessment (Wilby and Dawson 2013). Based on literature review, downscaling can be grouped into two broad categories; statistical and dynamic downscaling (Christensen et al. 1997; Fowler et al. 2007).

Dynamical downscaling (DD) involves use of high resolution Regional Climate Model (RCM) to simulate physical processes at fine spatial scale $(<50 \mathrm{~km})$ from the host GCM (Giorgi 1990; Jones et al. 1995). The major drawbacks of RCM are its complex design and computationally expensive nature (Hewitson and Crane 1996; Ghosh and Mishra 2010). In statis tical downscaling (SD), a statistical/empirical relationship is established between GCMs simulated large scale atmospheric variables (predictors) such as specific humidity, temperature, geo-potential height, etc., with station (local) scale meteorological variables (predictands) such as temperature and precipitation (Kim et al. 1984; von Storch et al. 2000; Jain et al. 2009). Based on these statistical/ empirical relationships, local scale predictands such as temperature can be downscaled at specific site or station. SD approach has shown advantage over DD approach as it is faster and simpler in use, less computationally expensive and applicable for uncertainty and risk analyses (Wilby et al. 2000; Yarnal et al. 2001). The requirement of long-time series of historical weather stations data is a serious drawback of this approach (Mahmood and Babel 2013).

Further, SD approach has been classified into three subcategories; weather typing, weather generator and regression/transform function (Wilby and Wigley 1997). The strength and weakness of each approach have been reviewed in more detail by (Hewitson and Crane 1996; Wilby and Wigley 1997; Wilby et al. 2002; Fowler et al. 2007). Statistical Downscaling Model (SDSM) is a combination of Multiple Regressions (MLR) and Stochastic Weather Generator (SWG) based downscaling methods (Wilby et al. 2002). It has been widely used throughout the world to downscale single-site scenarios of daily surface weather variables from predictors of GCMs for assessing hydrologic responses in climate change scenarios (Dibike and Coulibaly 2005; Gagnon et al. 2005; Aherne et al. 2008; Combalicer et al. 2010; Huang et al. 2011; Hashmi et al. 2011; Goyal et al. 2012). A couple of studies, one by Meenu et al. (2012) and another by Mahmood and Babel (2013), were conducted using SDSM in Indian subcontinent. They downscaled daily $T_{\mathrm{Max}}, T_{\mathrm{Min}}$ and precipitation (PCP) from predictors of Hadley Centre Coupled Model, version 3 (HadCM3) under A2 and B2 scenarios to access hydrological impacts of climate change in TungaBhadra River Basin, India and in Jhelum Basin, Pakistan-India respectively.

Sutlej Basin, a mountainous river basin is located in N-W Himalayan region. Recent studies performed over N-W Himalayan region using observed instrumental records revealed rise in mean surface annual temperature and decrease in summer precipitation (Bhutiyani et al. 2007, 2009). This variability in temperature and precipitation has altered the flow of Sutlej River and resulted in the decrease of mean annual and summer discharge respectively (Bhutiyani et al. 2008). The limited numbers of studies on future projections of temperature and precipitation have been performed over this region. The study conducted over East Asian region by Kripalani et al. (2007a) based on Intergovernmental Panel on Climate Change (IPCC) Assessment Report Four (AR4) models predicted significant change in mean annual precipitation. However, changes in mean precipitation varies from model to model $(-0.6 \%$ for Centre National de Recherches Météorologiques Coupled Model Version 3 (CNRM-CM3) and 14\% for ECHO-G and HadCM3) respectively. Further, a rise of $8 \%$ in mean monsoon precipitation was reported under doubling of $\mathrm{CO}_{2}$ scenario by Kripalani et al. (2007b). Based on the result derived from 5 GCMs, Sarthi et al. (2012) observed rise in mean annual temperature (in the range of $0.6^{\circ}-1.8^{\circ} \mathrm{C}$ ) over the Himalayan and Tibetan region for the future period. In this line of research, Kulkarni et al. (2013) used PRECIS (Providing Regional Climates for Impact Studies) RCM model and predicted increase in temperature and summer monsoon precipitation for entire HKH (Hindu Kush Himalayan) region under A1B emission scenario. The warming is projected in the range of $0.5^{\circ}-1^{\circ} \mathrm{C}$ for $2020 \mathrm{~s}(2011-2040), 1^{\circ}-3^{\circ} \mathrm{C}$ for $2050 \mathrm{~s}$ (2041-2070) and $4^{\circ}-5^{\circ} \mathrm{C}$ for 2080s (2071-2099), respectively. But till today, to the best of the knowledge of the authors, no studies has so far been carried out for downscaling of daily $T_{\mathrm{Max}}, T_{\mathrm{Min}}$ and precipitation using SDSM in Sutlej River Basin. This may be due to inaccessibility and scarcity of well distributed meteorological stations, nonavailability of past records of climate data and complex physiographic and climatic conditions prevailing in the basin.

The main purpose of the present study is: (1) to examine potential applicability of SDSM in daily downscaling of $T_{\text {Max }}, T_{\text {Min }}$ and PCP in a part of Sutlej River Basin (N-W Himalayan region), India, (2) to investigate efficacy of outputs of third generation Canadian Coupled Global Climate Model 
(CGCM3) and Hadley Centre Coupled Model, version 3 (HadCM3) in downscaling of $T_{\text {Max }}, T_{\text {Min }}$ and PCP using SDSM and (3) to investigate future changes on $T_{\text {Max }}, T_{\text {Min }}$ and $\mathrm{PCP}$ under various emission scenarios (A1B and A2 of CGCM3 and $\mathrm{A} 2$ and B2 of HadCM3) for the 21st century.

\section{Study area}

The study area is a part of Sutlej Basin that is locked up in the hilly state of Himachal Pradesh, India. Himachal Pradesh is divided into five distinct physiographic units: (1) Alluvial Plains (the southernmost zone developed at the foothills of Siwalik Range), (2) Sub-Himalayan zone, (3) Lesser Himalayan zone, (4) Central/Great Himalayan zone, and (5) Trans-Himalayan zone. Sutlej River which originates from Mansarovar-Rakastal lakes (western Tibet) at an altitude of $4570 \mathrm{~m}$ flows in north-west direction through rugged and dissected terrain of the Central and Lesser Himalayan ranges before joining the Indus River a few kilometers above Mithankot in Pakistan. The major part of this river lies in Indian territory $(1050 \mathrm{~km})$ and remaining in Tibet and Pakistan respectively.

Sutlej River is a perennial river. It receives water from glaciers and precipitation during summer and ground flow during winter. The salient characteristics of the whole Sutlej catchment (up to Bhakara Dam) are summarized in table 1 (Goswami 2007).

The Sutlej run-off basically consists of two parts, one part is derived from the melting of the snow and the other results from the rainfall in the catchment. Snow and glacier melt has significant contribution in stream flow and it varies from season to season, being the maximum in summer months. However, during monsoon, the lower part of the basin is generally characterized by high river flows and occasional floods due to excessive precipitation.

Sutlej Basin has the highest potential for hydropower generation as compared to other basins of Indus river system due to its unique topographical setting and availability of abundant water. Hence, several hydropower projects have been installed or planned to be installed on this river. The hydropower potential of river Sutlej and its tributaries has been estimated as 10268.5 MW out of which only 3267.5 MW is being harnessed (SANDRP 2014). Besides, the projects of $357 \mathrm{MW}$ are under construction and $3944 \mathrm{MW}$ is proposed to be installed on various stages of the Sutlej River. Future change in pattern and amount of temperature and precipitation would have significant implications over river discharge which may affect sectors like agriculture and hydropower generation in the basin. This present study is performed over middle part of the basin extending from Rampur to Kasol. It has a spread of $2457 \mathrm{~km}^{2}$ and lies between $31^{\circ} 05^{\prime} 00^{\prime \prime}-31^{\circ} 39^{\prime} 26^{\prime \prime} \mathrm{N}$ latitudes and $76^{\circ} 51^{\prime} 11^{\prime \prime}-77^{\circ} 45^{\prime} 17^{\prime \prime} \mathrm{E}$ longitudes (figure 1).

It falls between Lesser Himalayan zone and Central Himalayan zone and is characterized by tropical to temperate climate. The mean annual rainfall in the basin (study area) is $103 \mathrm{~cm}$ and more than $65 \%$ of its annual rainfall is received from southwest monsoon during months of June, July, August and September. $14.63 \%$ precipitation has been recorded during winter season (December, January and February) and it mainly occurs due to western disturbances.

\section{Data availability, sources and validation}

The station based observed daily time series of temperature $\left(T_{\mathrm{Max}}\right.$ and $\left.T_{\mathrm{Min}}\right)$ and PCP data for the period 1970-2005 are acquired for three stations namely, Kasol, Sunni and Rampur from Bhakara Beas Management Board (BBMB), India. This data is used as predictands in SDSM model. For this study, only those stations are included that have a complete data record over the period 1970-2000 and are at least 95\% complete within each year. Stations with a consistent observation time are considered for maintaining uniformity between predictands and predictors. The missing data wherever found is filled by using temporal interpolation method (daily value is computed as an average of the same day for a period between \pm 2

Table 1. The salient topographical and hydrometeorological features of the Sutlej Basin up to Bhakara Dam.

\begin{tabular}{lcccc}
\hline Reach & $\begin{array}{c}\text { Catchment } \\
\text { area }\left(\mathrm{km}^{2}\right)\end{array}$ & $\begin{array}{c}\text { Elevation } \\
\text { range }(\mathrm{m})\end{array}$ & $\begin{array}{c}\text { Average annual } \\
\text { rainfall }(\mathrm{mm})\end{array}$ & $\begin{array}{c}\text { Major source of contributions } \\
\text { to the stream flow }\end{array}$ \\
\hline Tibetan Plateau & 37050 & $4000-6000$ & Nil & Snow and glacier \\
Spiti Valley & 7084 & $3300-5300$ & Scarce & Snow and glacier \\
Namgia to Rampur & 6490 & $3000-4800$ & Little & Snow and rainfall \\
Rampur to Sunni & 2068 & $1200-3000$ & $1000-1500$ & Rainfall \\
Sunni to Kasol & 700 & $900-2000$ & $910-1630$ & Rainfall \\
Kasol to Bhakhra & 3108 & $600-2000$ & 1520 & Rainfall \\
\hline
\end{tabular}




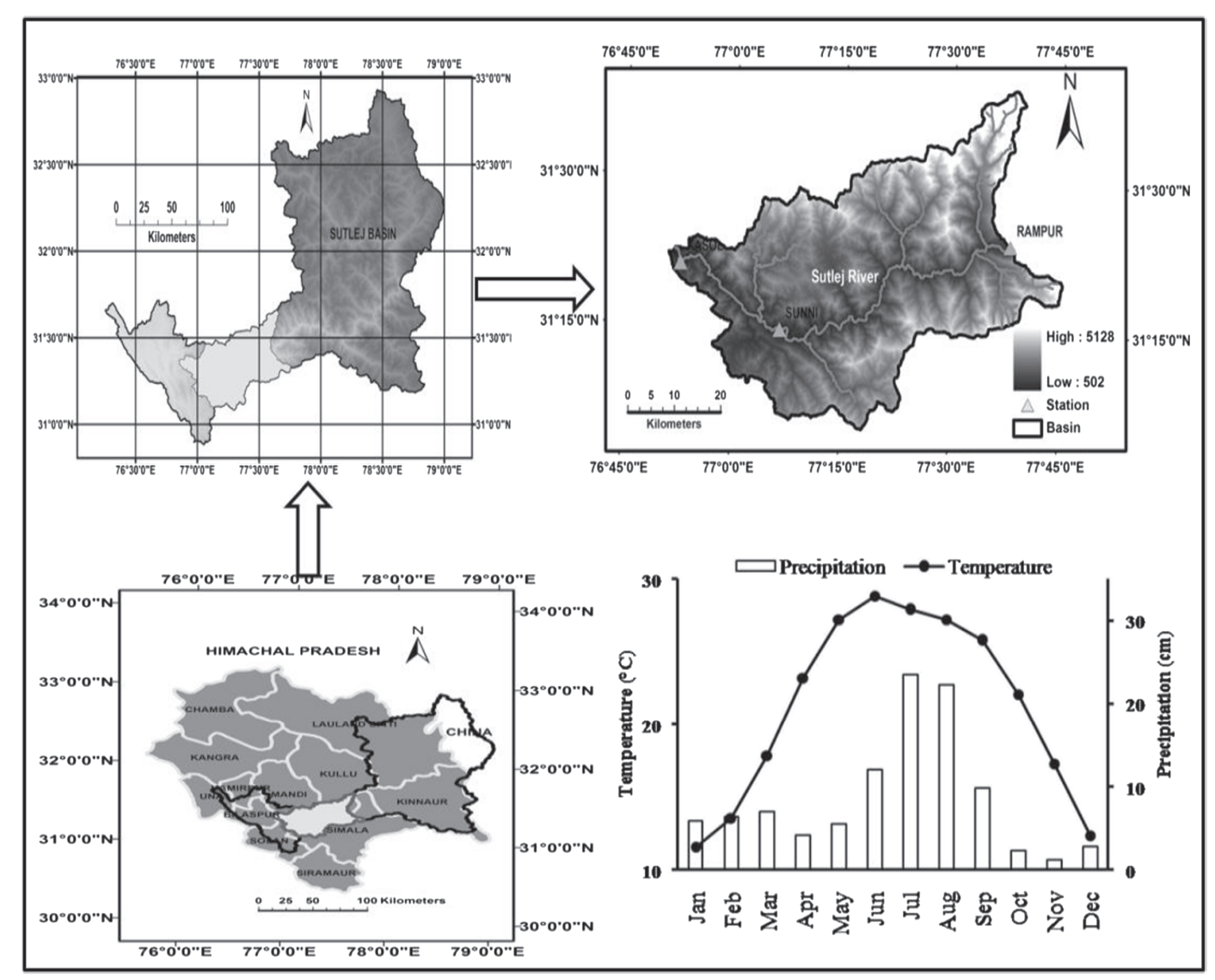

Figure 1. Location map of the study area with prevailed climatic characteristics.

Table 2. Geographic and climatic information of stations in Sutlej basin.

Average annual

Elevation temperature $\left({ }^{\circ} \mathrm{C}\right)$ Average annual

Seasonal PCP $(\mathrm{cm})$

\begin{tabular}{llllllcrrr} 
Station & Latitude & Longitude & $(\mathrm{m})$ & $T_{\text {Max }}$ & $T_{\text {Min }}$ & & PCP $(\mathrm{cm})$ & & Pre-monsoon Monsoon Post-monsoon Winter \\
\hline Kasol $31^{\circ} 21^{\prime} 25^{\prime \prime} 76^{\circ} 52^{\prime} 42^{\prime \prime}$ & 662 & 28.55 & 16.79 & & 132.26 & 14.82 & 85.65 & 17.14 \\
Sunni $31^{\circ} 14^{\prime} 15^{\prime \prime} 77^{\circ} 06^{\prime} 30^{\prime \prime}$ & 655 & 29.02 & 12.27 & & 101.47 & 14.65 & 54.43 & 13.16 \\
Rampur $31^{\circ} 27^{\prime} 15^{\prime \prime} 77^{\circ} 38^{\prime} 40^{\prime \prime}$ & 976 & 27.17 & 13.66 & & 76.34 & 15.90 \\
\hline
\end{tabular}

years). The geographic and climatic characteristics of these stations are described in table 2 .

The limitations of well-distributed stations along with prevailed variations in altitude and physiographic conditions among available stations demand for executing homogeneity test with data of individual station and other stations in order to establish spatial and temporal compatibility in observations (Mutreja 1986; van der Made 1987). The techniques such as double mass-curves, simple linear correlation and regression analyses suggested by Bhutiyani et al. (2009) are used for this purpose. The plotted graphs of double mass-curves performed for the three stations with each other show straight lines. Besides, positive bivariate correlations in linear regressions are observed between the stations as shown in table 3 . This reveals high temporal and spatial uniformity in the inter-annual variability of temperature and precipitation data at all the three stations.

The predictors used in this study are: (1) observed predictors obtained from National Centre for Environmental Prediction/National Centre for Atmospheric Research (NCEP/NCAR) reanalysis gridded datasets, and (2) modelled predictors obtained from CGCM3 and HadCM3 models. The predictor variables for nearest grid in the study area are obtained from the websites of Data Access Integration (DAI) (http://loki.qc.ec. gc.ca/DAI/predictors-e.html) and Canadian Climate Impacts Scenarios (CCIS) (http://www. cics.uvic.ca/scenarios/index.cgi), respectively. The predictors simulated by CGCM3 model and HadCM3 model are available on grid resolution $3.75^{\circ}$ lat. $\times 3.75^{\circ}$ long. and $2.5^{\circ}$ lat. $\times 3.75^{\circ}$ long. respectively. The study area is registered within 
Table 3. Statistics of bivariate correlation $\left(r^{2}\right)$ analysis computed over Kasol, Sunni and Rampur at $95 \%$ confidence level.

\begin{tabular}{|c|c|c|c|c|c|c|c|c|c|c|c|}
\hline \multicolumn{4}{|c|}{$T_{\mathrm{Max}}$} & \multicolumn{4}{|c|}{$T_{\mathrm{Min}}$} & \multicolumn{4}{|c|}{ PCP } \\
\hline & Kasol & Sunni & Rampur & & Kasol & Sunni & Rampur & & Kasol & Sunni & Rampur \\
\hline Kasol & 1 & 0.89 & 0.90 & Kasol & 1 & 0.91 & 0.92 & Kasol & 1 & 0.1 & 0.06 \\
\hline Sunni & 0.89 & 1 & 0.90 & Sunni & 0.91 & 1 & 0.94 & Sunni & 0.1 & 1 & 0.48 \\
\hline Rampur & 0.90 & 0.90 & 1 & Rampur & 0.92 & 0.94 & 1 & Rampur & 0.06 & 0.48 & 1 \\
\hline
\end{tabular}

grid box 21X_16Y (lat. $31.54^{\circ} \mathrm{N} \times 75.00^{\circ} \mathrm{E}$ long.) and box_22X_16Y (lat. $31.54^{\circ} \mathrm{N} \times 78.75^{\circ} \mathrm{E}$ long.) of CGCM3 model. Further, it is registered within grid box 21X_22Y (lat. $32.5^{\circ} \mathrm{N} \times 75.00^{\circ} \mathrm{E}$ long.), box_22X_23Y (lat. $30^{\circ} \mathrm{N} \times 78.75^{\circ} \mathrm{E}$ long.) and box $22 \mathrm{X} \_22 \mathrm{Y}$ (lat. $32.5^{\circ} \mathrm{N} \times 78.75^{\circ} \mathrm{E}$ long.) of HadCM3 model.

The predictors are simulated under historical GHG and aerosol concentration experiment for 20th century run (20C3M) as well as Special Report on Emission Scenarios (SRES) for future run. The future scenarios considered in this study are $\mathrm{A} 1 \mathrm{~B}$ and $\mathrm{A} 2$ for CGCM3 model and A2 and B2 for HadCM3 model respectively. The NCEP/ NCAR reanalysis datasets have a grid spacing of $1.9^{\circ}$ latitude $\times 1.9^{\circ}$ longitude. The NCEP/ NCAR reanalysis predictors have to be re-gridded to conform to the grid-spacing of CGCM3 and HadCM3 models. The re-gridded and standardized predictors were supplied in the zip file. The standardization of predictors is carried out before statistical downscaling to minimize biases in mean and variance of CGCM3 and HadCM3 predictors with respect to that of $\mathrm{NCEP} / \mathrm{NCAR}$ reanalysis data. All the predictor variables are normalized over 1961-1990 periods which is taken as base line period. The predictor variables are available on daily time step for period 19612100 for CGCM3 model, 1961-2099 for HadCM3 model and 1961-2001/2003 for NCEP/NCAR, respectively.

\section{Methodology}

\subsection{Description of statistical downscaling model (SDSM)}

SDSM which started its life in summer 2000 was developed by R L Wilby and C W Dawson. A combination of MLR and SWG methods are used in this model (Wilby et al. 2002). MLR is used to establish empirical relationship between predictors and predictands of interest and generate regression parameters, whereas SWG is applied to simulate up to 100 daily time series from predictors of NCEP/NCAR and GCMs based on these regression parameters (Mahmood and Babel 2013). The algorithms used in SDSM and presented here have been discussed in detail by Wilby and Dawson (2013).

In SDSM, generation of station scale weather parameters is linearly conditioned by observed large scale predictors of atmosphere $(j=1,2, \ldots, n)$. The downscaled process is either unconditional or conditional. The downscaling for the conditional process like daily PCP depends on an intermediate variable such as occurrence of a wet day. The occurrence of wet day $\left(W_{i}\right)$ on day $i$ is linearly dependent on predictors $X_{i j}$.

$$
W_{i}=\alpha_{0}+\sum_{j=1}^{n} \alpha_{j} X_{i j},
$$

under the constraint $0 \leq W_{i} \leq 1$. The value of $W_{i}$ varies according to prevailing large-scale weather conditions (represented by the predictor variables) between 0 and 1 . The precipitation will occur if uniform random number $r \leq W_{i} . W_{i}$ is not a Boolean (0 or 1$)$ number but is a continuous variable between 0 and 1 . For example, on a day with high pressure, $W_{i}$ might be equal to 0.2 . Then, $r$ is used to determine whether a rain day will actually occur depending upon whether $r \leq 0.2$.

The amount of total $\overline{P C P}\left(P_{i}\right)$ downscaled on day $i$ with return of wet day is shown in equation (2):

$$
P_{i}^{k}=\beta_{0}+\sum_{j=1}^{n} \beta_{j} X_{i j}+\varepsilon_{i}
$$

where $k$ is a transformation (fourth root, inverse normal or logarithmic) which is applied as PCP data is skewed in nature. In case of unconditional processes like daily temperature $\left(T_{\text {Max }}\right.$ and $\left.T_{\text {Min }}\right)$, a direct linear relationship is established between the predictand $U_{i}$ and selected NCEP/NCAR predictors $X_{i j}$ on individual sites such as:

$$
U_{i}=\gamma_{0}+\sum_{j=1}^{n} \gamma_{j} X_{i j}+\varepsilon_{i}
$$

where $U_{i}$ is temperature on day $i$ and $X_{i j}$ is selected $\mathrm{NCEP} / \mathrm{NCAR}$ predictors on day $i . \alpha_{j}, \beta_{j}$ and $\gamma_{j}$ are regression coefficients estimated for each month using least-squares regression and $\varepsilon_{i}$ is model error. It is generated stochastically using a series of serially independent Gaussian numbers and is 


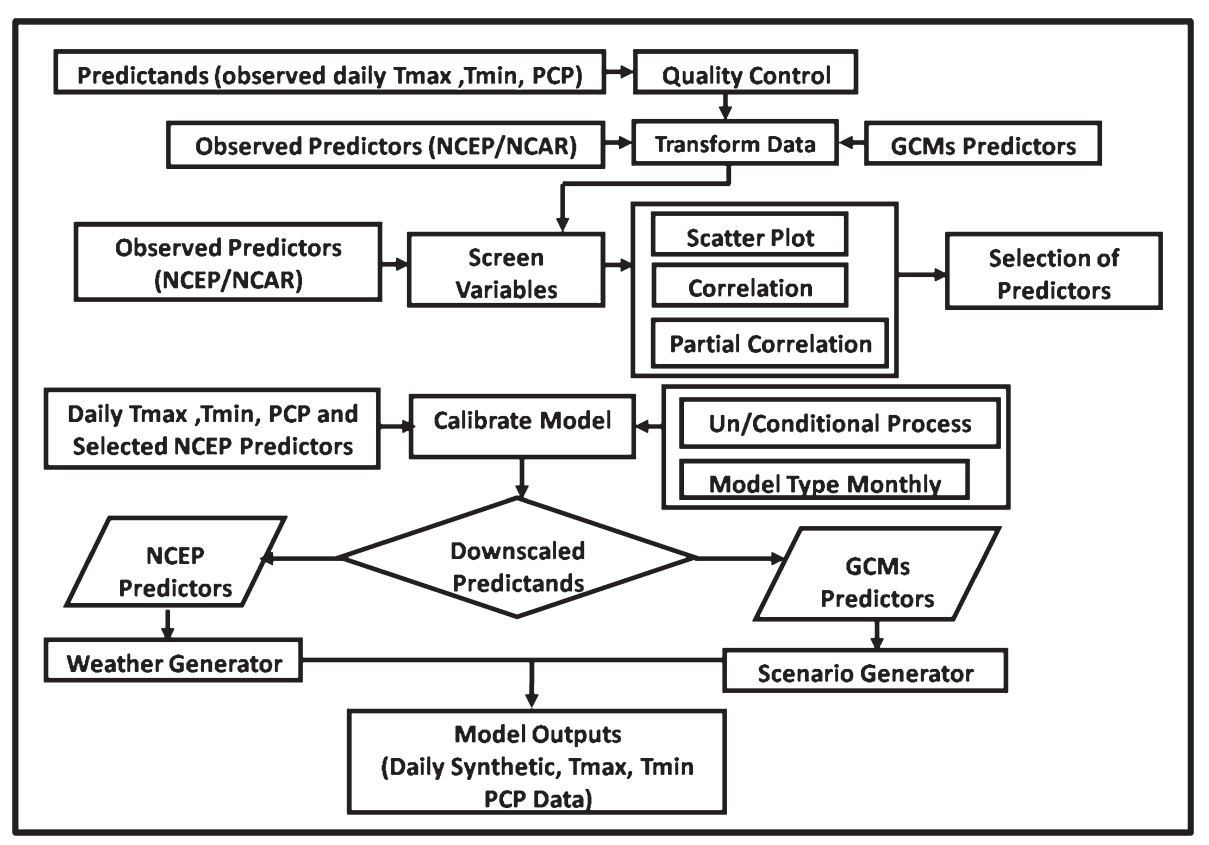

Figure 2. Flow chart showing steps involved in downscaling and scenario generation (modified after Wilby and Dawson 2007).

added to the deterministic components on daily basis.

The major steps adopted for downscaling of $T_{\mathrm{Max}}, T_{\mathrm{Min}}$ and PCP involve: (1) quality check, transformation, screening of probable predictors, (2) calibration of monthly submodel using station scale $T_{\mathrm{Max}}, T_{\mathrm{Min}}$ and PCP data and selected predictors of NCEP/NCAR, (3) generation of present and future time series for $T_{\mathrm{Max}}, T_{\mathrm{Min}}$ and PCP from the gridded datasets of NCEP/NCAR and GCMs (CGCM3 and HadCM3), and (4) statistical analysis of downscaled projected $T_{\mathrm{Max}}, T_{\mathrm{Min}}$ and PCP at each individual station. The various steps followed in the present study for downscaling and scenario generation are shown in figure 2 .

\subsubsection{Quality control check, transformation and screening of probable predictors}

Station-based meteorological data may have errors in terms of missing records or outliers. Quality control check function is used to identify such errors prior to model calibration. The missing data may be replaced by a data identifier code, i.e., -999. In some cases, transformation of predictors or predictands may be of significant interests. SDSM provides facility to transform data before calibration using different types of transformations such as logarithm, power, inverse, lag, binomial, etc. After quality control check and transformation, screen variable operation is applied to select appropriate sets of observed predictors from the suite of NCEP/NCAR reanalysis datasets based on scatter plots, correlation and partial correlation statistics (Wilby and Dawson 2007).

\subsubsection{Calibration of monthly submodel using station scale $T_{M a x}, T_{M i n}$ and PCP data and selected predictors of NCEP/NCAR}

SDSM is calibrated using observed station scale data ( $T_{\text {Max }}, T_{\text {Min }}$ and PCP) and screened sets of observed predictors, i.e., NCEP/NCAR reanalysis datasets. SDSM offers three different types of submodels; (1) monthly, (2) seasonal, and (3) annual for the downscaling of predictands $\left(T_{\mathrm{Max}}, T_{\mathrm{Min}}\right.$ and PCP) from the large scale predictors. The monthly submodel derives 12 different regression equations, one for each month, whereas seasonal submodel generates four different regression equations, one for each season. In case of annual submodel, a single regression equation is generated for all 12 months having same model parameters. The process involved in downscaling may be either unconditional (e.g., $\left.T_{\mathrm{Max}}, T_{\mathrm{Min}}\right)$ or conditional (e.g., PCP). There are two methods for optimizing SDSM; (1) Dual Simplex and (2) Ordinary Least Squares. Both the methods provide comparable results but Ordinary Least Squares is much faster and has been used in the present study.

Further, monthly submodel type is preferred because there are large monthly variations in $T_{\text {Max }}, T_{\text {Min }}$ and PCP at different stations within the study region. In monthly submodel, identical sets of predictors and predictands generate different statistical values for each month. This may be 
attributed to the fact that different empirical relationships are constructed for different months of the year by this model. The values of $E(\%)$ are used to explain how and to what extent daily variations in predictands are determined by regional forcing.

\subsubsection{Generation of present and future time series for $T_{M a x}, T_{M i n}$ and $P C P$ from the gridded datasets of NCEP/NCAR and GCMs}

After calibrating the model, Weather Generator function is applied to generate ensembles of synthetic daily time series of $T_{\mathrm{Max}}, T_{\mathrm{Min}}$ and PCP representing present climate from screened sets of NCEP/NCAR predictors. The synthetically generated daily time series of $T_{\mathrm{Max}}, T_{\mathrm{Min}}$ and PCP is compared (in terms of statistics) with observed records to know how close it is to the present climate. Finally, Scenario Generator function is used to simulate future time series of $T_{\mathrm{Max}}, T_{\mathrm{Min}}$ and PCP using outputs of GCMs (CGCM3 and HadCM3) on daily time-step under different emission scenarios.

\subsubsection{Statistical analysis of downscaled projected $T_{M a x}, T_{M i n}$ and $P C P$}

At the end, various statistical operations were performed on downscaled projected time series of $T_{\mathrm{Max}}, T_{\mathrm{Min}}$ and PCP in order to see changes observed in climate of the study area.

\section{Results and discussions}

This section describes screening of predictors, calibration and validation of SDSM model used for downscaling of $T_{\text {Max }}, T_{\text {Min }}$ and PCP. The performance of developed SDSM along with downscaled results are discussed for future periods; 2020s (2011-2040), 2050s (2041-2070) and 2080s (2071-2099) under A2, A1B and B2 emission scenarios. A comparison between downscaled results of CGCM3 model and HadCM3 model is also made under a common emission scenario, i.e., A2.

\subsection{Screening of predictors}

In statistical downscaling, screening of suitable predictors for downscaling predictands is one of the most important steps (Hewitson and Crane 1996). The explanatory power of individual predictor variable varies both spatially and temporally (Wilby et al. 2002). The choice of predictors can be different for different geographical regions depending on the properties of the predictor and the predictand to be downscaled (Anandhi et al. 2009).

The qualitative (e.g., scatter plots) as well as quantitative (e.g., value of explained variance for different months, correlation, partial correlation $(r)$ and $P$ values) approaches mentioned by Mahmood and Babel (2013) are adopted for obtaining the most suitable sets of predictors from the suite of NCEP/NCAR predictors at an individual station. The explained variance explains the level to which daily variations in the predictand are determined by predictors (Wilby et al. 2002). The correlation statistics and $P$ values are used to explain the strength of relationship between the predictor and predictand. The high $P$ value signifies that the predictor-predictand correlation could be chance related while the smaller $P$ values describe a better chance for association between variables. This has been explained in detail with an example. The procedure involved in screening of NCEP/NCAR predictors for downscaling of PCP at Rampur station of HadCM3 model is shown in table 4.

- A super predictor (SP) is chosen based on correlation coefficient (R1) between predictors of NCEP/NCAR and predictand (PCP). The predictor having highest correlation coefficient among all the predictors ( 8 in this case) arranged in descending order is defined as SP. For PCP, relative humidity at $850 \mathrm{hpa}$ (r850) is defined as $\mathrm{SP}$ at Rampur station.

- In the presence of SP, values of correlation coefficient between predictors and predictand $(R 1)$,

Table 4. Procedure adopted in screening of NCEP/NCAR predictors (in case of HadCM3 model) for precipitation at Rampur station.

\begin{tabular}{|c|c|c|c|c|c|c|}
\hline Sl. no. & Predictor & $R 1(\%)$ & $R^{2}(\%)$ & $\operatorname{Pr}(\%)$ & $P$ value & $\operatorname{PRP}(\%)$ \\
\hline 1. & $850 \mathrm{hPa}$ relative humidity ( $\mathrm{r} 850$ ) & 19.5 & - & - & 0.00 & - \\
\hline 2. & $500 \mathrm{hPa}$ divergence $(\mathrm{p} 5 \mathrm{zh})$ & 17.9 & 41.9 & 5.18 & 0.00 & 44.6 \\
\hline 3. & $500 \mathrm{hPa}$ relative humidity ( $\mathrm{r} 500$ ) & 14.8 & 71.6 & 6.19 & 0.07 & 68.9 \\
\hline 4. & Surface air flow strength (p_f) & 14.8 & 43.2 & 6.16 & 0.38 & 86.4 \\
\hline 5. & 850 hPa zonal velocity (p8_u) & 11.1 & 31.7 & 5.29 & 0.47 & 14.6 \\
\hline 6. & 850 hPa vorticity (p8_z) & 10.8 & 28.5 & 5.12 & 0.48 & 11.1 \\
\hline 7. & Surface wind direction (p_th) & 9.5 & 14.8 & 6.19 & 0.44 & 83.1 \\
\hline 8. & Mean sea level pressure (mslp) & 9.1 & 10.1 & 6.07 & 0.00 & 3.2 \\
\hline
\end{tabular}


between individual predictors $\left(R^{2}\right)$, partial correlation $(r)$ and $P$ value are obtained by regression from the left over highly correlated predictors $(7$ in this case) as shown in table 4 above.

- The effect of multi-colinearity in remaining predictors is minimized by eliminating those predictors which show high correlation with SP. This is subjective in nature and in some studies the correlation coefficient up to 0.7 is acceptable. As discussed in the methodology section, the predictors having high $P$ values $(>0.03)$ are also taken away in order to keep results statistically significant.

- Percentage reduction in partial correlation (PRP) for each predictor is derived from the equation given below:

$$
\mathrm{PRP}=\frac{\operatorname{Pr}-R 1}{R 1}
$$

where, $\operatorname{Pr}$ stands for partial correlation coefficient and $R 1$ for correlation coefficient.

- The screening of the most appropriate second predictor is made on the basis of PRP value. The predictor having minimum PRP value is selected as second most appropriate predictor. The mean sea level pressure (mslp) is found to be the second most suitable predictor for downscaling of precipitation at Rampur.

- The selection of third, fourth and other predictors is done by repeating the steps from 2 to 5 .

The predictors lagged by -1 day are also created for variables like mean temperature and specific humidity using transform function. The predictors thus screened using the above procedure for HadCM3 is shown in table 5.

In the same way, the predictors are screened for CGCM3 model which are shown in table 6 .

These screened sets of relevant predictors for both the models are then used for downscaling of $T_{\text {Max }}, T_{\text {Min }}$ and precipitation at individual station.

\subsection{Calibration and validation of model}

The screened sets of daily NCEP/NCAR predictors and predictands $\left(T_{\mathrm{Max}}, T_{\mathrm{Min}}\right.$ and PCP) are employed for model calibration using 21 years data (1970-1990). The model is validated using remaining 10 years data (1991-2000) of NCEP/NCAR and simulation data, i.e., 20C3M scenario for CGCM3 and HadCM3 models respectively. During the calibration process, monthly submodel is developed and downscaling process is selected as unconditional process for temperature while it is conditional for PCP. The fourth root transformation is applied to the original PCP data to convert it to a normal distribution. A total of 20 ensembles are produced and the mean of these ensembles is

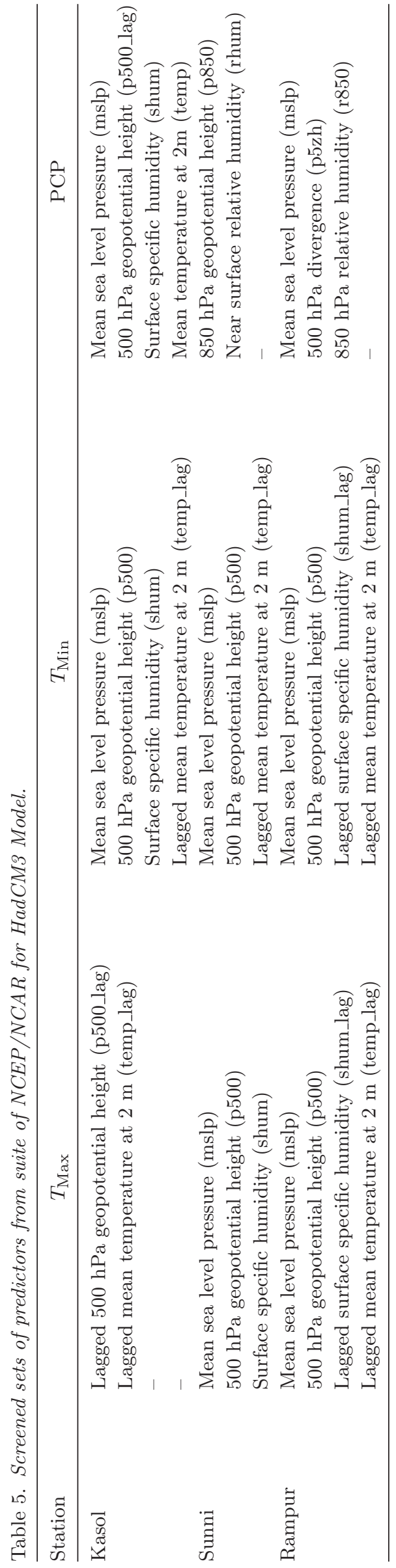




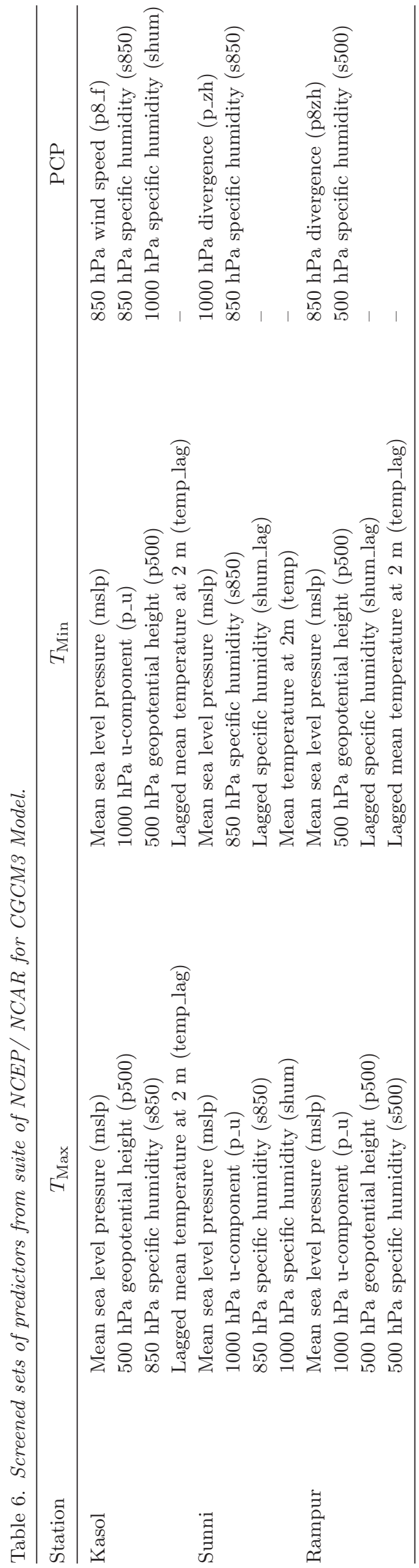

used. The results (averaged over three stations) obtained during calibration and validation are given in tables 7 and 8 respectively.

The values of explained variance $E(\%)$ and standard error (SE) determine credibility of the results as values of $E(\%)$ are used to explain how and to what extent daily variations in predictands are determined by regional forcing (Wilby et al. 2002). There is significant seasonal variations in the results as comparatively low values of $E(\%)$ are measured for $T_{\mathrm{Max}}, T_{\mathrm{Min}}$ and PCP during months of June, July, August and September, i.e., monsoon season. This may be attributed to the inherent errors in simulated precipitation fields as GCMs show deficiencies in representation of the Indian monsoon that is one of the most dominant tropical circulation systems in the general circulation of the atmosphere (Dai 2006; Rajeevan and Nanjundiah 2009).

The computed mean monthly value of $E(\%)$ during calibration for $T_{\mathrm{Max}}, T_{\mathrm{Min}}$ and PCP are $49.3 \%$, $54.5 \%$ and $9.5 \%$ for CGCM3 and $49.1 \%, 57.9 \%$ and $10.0 \%$ for HadCM3 model respectively. Generally, the value of explained variance $(E \%)$ are found between $67 \%$ to $90 \%$ (Gagnon et al. 2005; Combalicer et al. 2010; Meenu et al. 2012) for temperature ( $T_{\mathrm{Max}}$ and $T_{\mathrm{Min}}$ ) and 10-30\% (Wilby et al. 2002; Masoud et al. 2008; Huang et al. 2011) for precipitation. The results obtained in the present study are closer to such levels.

\subsection{Statistical comparison of downscaled results during calibration and validation}

The statistical measures, namely, coefficient of determination $\left(R^{2}\right)$, root mean square error (RMSE), mean absolute percentage error (MAPE), mean $(\mu)$, standard deviation (SD), standard error of mean (SE_ $\mu$ ) and mean absolute deviation (MAD) are used to compare observed data with downscaled data during calibration and validation period. The value of $R^{2}$ is indicative of strength between observed and downscaled (simulated) values whereas RMSE and MAPE are used to determine accuracy of the model. $R^{2}$ value explains correlation between the observed and downscaled values and lies between 0 (poor) to 1 (best). However, $\mu$ and $\mathrm{SE}_{-} \mu$ are exercised to test how well the model predicted the mean values, while SD and MAD are used to investigate variability of data simulated by the model. The discussed statistical measures are first computed for each station and then the mean values of each statistical measure are attained from all the stations.

Table 9 shows comparison between statistical measures of observed and downscaled NCEP/NCAR for mean monthly $T_{\mathrm{Max}}, T_{\mathrm{Min}}$ and $\mathrm{PCP}$ during 
Table 7. Monthly explained variance (E\%) and standard error (SE) averaged over three stations for different months during calibration (1970-1990).

\begin{tabular}{|c|c|c|c|c|c|c|c|c|c|c|c|c|c|c|c|}
\hline Model & Variables & Month & $\mathrm{J}$ & $\mathrm{F}$ & M & $\mathrm{A}$ & M & $\mathrm{J}$ & $\mathrm{J}$ & A & $\mathrm{S}$ & $\mathrm{O}$ & $\mathrm{N}$ & Dec & Mean \\
\hline \multirow{6}{*}{ CGCM3 } & \multirow[t]{2}{*}{$T_{\text {Max }}$} & $\mathrm{E}(\%)$ & 42.1 & 46.7 & 57.5 & 64.7 & 61.8 & 51.3 & 36.8 & 31.3 & 39.6 & 55.9 & 56.3 & 50.3 & 49.3 \\
\hline & & $\mathrm{SE}\left({ }^{\circ} \mathrm{C}\right)$ & 2.8 & 2.9 & 3.1 & 2.4 & 2.6 & 2.5 & 2.5 & 2.3 & 2.1 & 1.8 & 2.0 & 2.3 & 2.4 \\
\hline & \multirow[t]{2}{*}{$T_{\text {Min }}$} & $\mathrm{E}(\%)$ & 49.2 & 59.8 & 60.0 & 63.6 & 48.8 & 46.0 & 25.5 & 35.2 & 65.3 & 72.4 & 68.0 & 59.3 & 54.5 \\
\hline & & $\mathrm{SE}\left({ }^{\circ} \mathrm{C}\right)$ & 1.5 & 1.6 & 1.9 & 1.8 & 2.3 & 1.9 & 1.4 & 1.2 & 1.4 & 1.4 & 1.4 & 1.4 & 1.6 \\
\hline & \multirow[t]{2}{*}{ PCP } & E (\%) & 12.8 & 12.5 & 9.9 & 5.4 & 5.5 & 8.2 & 8.6 & 7.1 & 10.2 & 12.8 & 10.6 & 11.9 & 9.5 \\
\hline & & $\mathrm{SE}(\mathrm{mm})$ & 0.4 & 0.4 & 0.4 & 0.4 & 0.4 & 0.5 & 0.5 & 0.5 & 0.5 & 0.4 & 0.3 & 0.4 & 0.4 \\
\hline \multirow{6}{*}{ HadCM3 } & \multirow[t]{2}{*}{$T_{\mathrm{Max}}$} & $\mathrm{E}(\%)$ & 42.1 & 45.9 & 57.4 & 63.7 & 62.0 & 51.1 & 35.4 & 30.2 & 38.5 & 55.6 & 56.3 & 50.7 & 49.1 \\
\hline & & $\mathrm{SE}\left({ }^{\circ} \mathrm{C}\right)$ & 2.8 & 2.9 & 3.1 & 2.4 & 2.6 & 2.5 & 2.5 & 2.3 & 2.1 & 1.8 & 2.0 & 2.3 & 2.4 \\
\hline & \multirow[t]{2}{*}{$T_{\mathrm{Min}}$} & $\mathrm{E}(\%)$ & 54.0 & 58.9 & 61.3 & 62.8 & 48.0 & 48.8 & 47.9 & 12.8 & 65.8 & 68.3 & 70.2 & 60.3 & 57.9 \\
\hline & & $\mathrm{SE}\left({ }^{\circ} \mathrm{C}\right)$ & 1.5 & 1.6 & 1.8 & 1.8 & 2.3 & 1.9 & 1.6 & 1.2 & 1.3 & 1.5 & 1.4 & 1.4 & 1.6 \\
\hline & \multirow[t]{2}{*}{$\mathrm{PCP}$} & $\mathrm{E}(\%)$ & 12.2 & 11.9 & 14.1 & 13.1 & 12.4 & 7.6 & 6.6 & 4.6 & 13.5 & 6.9 & 7.1 & 9.9 & 10.0 \\
\hline & & $\mathrm{SE}(\mathrm{mm})$ & 0.4 & 0.4 & 0.4 & 0.3 & 0.4 & 0.5 & 0.5 & 0.5 & 0.4 & 0.3 & 0.2 & 0.3 & 0.4 \\
\hline
\end{tabular}

Table 8. Monthly explained variance (E\%) and standard error (SE) averaged over three stations for different months during validation (1991-2000).

\begin{tabular}{|c|c|c|c|c|c|c|c|c|c|c|c|c|c|c|c|}
\hline Model & Variables & Month & $\mathrm{J}$ & $\mathrm{F}$ & M & $\mathrm{A}$ & M & $\mathrm{J}$ & $\mathrm{J}$ & A & $\mathrm{S}$ & $\mathrm{O}$ & $\mathrm{N}$ & Dec & Mean \\
\hline \multirow{6}{*}{ CGCM3 } & \multirow[t]{2}{*}{$\mathrm{T}_{\text {Max }}$} & $\mathrm{E}(\%)$ & 44.4 & 51.4 & 60.1 & 65.7 & 43.5 & 51.5 & 27.6 & 29.5 & 47.3 & 56.3 & 68.7 & 56.6 & 50.2 \\
\hline & & $\mathrm{SE}\left({ }^{\circ} \mathrm{C}\right)$ & 2.3 & 2.4 & 2.7 & 2.0 & 2.6 & 2.3 & 2.2 & 2.0 & 1.8 & 1.6 & 1.6 & 1.9 & 2.1 \\
\hline & \multirow[t]{2}{*}{$T_{\text {Min }}$} & $\mathrm{E}(\%)$ & 40.6 & 59.9 & 63.3 & 62.2 & 42.8 & 49.5 & 20.1 & 35.2 & 64.8 & 65.9 & 72.8 & 57.9 & 52.9 \\
\hline & & $\mathrm{SE}\left({ }^{\circ} \mathrm{C}\right)$ & 1.7 & 1.6 & 1.7 & 1.8 & 2.1 & 1.8 & 1.4 & 1.1 & 1.4 & 1.4 & 1.3 & 1.4 & 1.6 \\
\hline & \multirow[t]{2}{*}{ PCP } & $\mathrm{E}(\%)$ & 15.0 & 12.5 & 7.3 & 10.3 & 14.8 & 11.0 & 6.3 & 3.5 & 13.8 & 24.5 & 4.3 & 3.0 & 10.5 \\
\hline & & $\mathrm{SE}(\mathrm{mm})$ & 0.4 & 0.4 & 0.4 & 0.4 & 0.4 & 0.5 & 0.5 & 0.5 & 0.5 & 0.3 & 0.3 & 0.3 & 0.4 \\
\hline \multirow{6}{*}{ HadCM3 } & \multirow[t]{2}{*}{$T_{\text {Max }}$} & $\mathrm{E}(\%)$ & 34.3 & 48.6 & 65.8 & 57.9 & 48.7 & 47.6 & 20.7 & 22.0 & 31.3 & 39.4 & 60.6 & 39.5 & 44.1 \\
\hline & & $\mathrm{SE}\left({ }^{\circ} \mathrm{C}\right)$ & 2.8 & 2.7 & 3.1 & 2.5 & 2.7 & 2.9 & 2.4 & 2.4 & 2.1 & 2.0 & 1.8 & 2.1 & 2.5 \\
\hline & \multirow[t]{2}{*}{$T_{\mathrm{Min}}$} & $\mathrm{E}(\%)$ & 43.8 & 60.8 & 62.7 & 59.1 & 40.7 & 47.8 & 44.6 & 48.0 & 65.1 & 60.1 & 75.4 & 58.5 & 55.6 \\
\hline & & $\mathrm{SE}\left({ }^{\circ} \mathrm{C}\right)$ & 1.7 & 1.5 & 1.8 & 1.9 & 2.1 & 1.9 & 1.6 & 1.3 & 1.3 & 1.7 & 1.3 & 1.4 & 1.6 \\
\hline & \multirow[t]{2}{*}{ PCP } & $\mathrm{E}(\%)$ & 11.3 & 12.8 & 16.8 & 9.7 & 9.1 & 10.5 & 4.1 & 2.5 & 15.4 & 6.3 & 8.3 & 4.1 & 9.2 \\
\hline & & $\mathrm{SE}(\mathrm{mm})$ & 0.4 & 0.4 & 0.4 & 0.3 & 0.4 & 0.5 & 0.5 & 0.5 & 0.4 & 0.3 & 0.2 & 0.3 & 0.4 \\
\hline
\end{tabular}

calibration period under both the models. Temperature variables are downscaled and simulated better than precipitation as values of all statistical measures are much closer to the statistics of observed data. The values of low explained variance $(\leq 10 \%)$ obtained for precipitation during calibration have resulted in poor correlation $\left(R^{2} \leq 0.50\right)$ between observed and downscaled NCEP/NCAR data. This may be attributed to the spatially nonconservative nature of precipitation (Gagnon et al. 2005). However, high correlation coefficient and low RMSE error are gained for $T_{\text {Max }}\left(R^{2}>0.80\right.$ and RMSE $\left.<2.40^{\circ} \mathrm{C}\right)$ and $T_{\text {Min }}\left(R^{2}>0.90\right.$ and RMSE $<1.94^{\circ} \mathrm{C}$ ), respectively.

Similarly, results of comparison between observed and downscaled mean monthly $T_{\text {Max }}$, $T_{\mathrm{Min}}$ and PCP in terms of statistical measures for validation period are given in table 10 . In case of NCEP/NCAR data, the values of $R^{2}$ and RMSE are found in the range of $0.80-0.81$ and $2.49^{\circ}-$ $2.53^{\circ} \mathrm{C}$ for $T_{\text {Max }}$ and in the range of $0.88-0.89$ and $2.07^{\circ}-2.14^{\circ} \mathrm{C}$ for $T_{\text {Min }}$ respectively. For $20 \mathrm{C} 3 \mathrm{M}$, values of $R^{2}$ and RMSE are found in range of
$0.77-0.80$ and $2.63^{\circ}-2.80^{\circ} \mathrm{C}$ for $T_{\text {Max }}$ and in range of $0.89-0.93$ and $1.83^{\circ}-2.29^{\circ} \mathrm{C}$ for $T_{\mathrm{Min}}$ respectively. The higher value of $R^{2}$ is obtained for $T_{\text {Max }}$ and $T_{\text {Min }}$ under 20C3M scenario of CGCM3 model as compared to HadCM3 model. Besides, other statistical measures have also shown a good agreement with observed statistics but deviation of amount is noticed between them. However, comparatively low values of $R^{2} \leq 0.41$ (for NCEP/ NCAR and 20C3M) and high values of RMSE are obtained for precipitation under both the models.

\subsection{Bias correction}

The downscaled data inherited uncertainties due to parameterizations of GCMs and limitations of SDSM model in defining complex physical processes through empirical relationships. Therefore, the model is unable to downscale and simulate climate variables $\left(T_{\mathrm{Max}}, T_{\mathrm{Min}}\right.$ and $\left.\mathrm{PCP}\right)$ accurately. Difference between observed and simulated climate 
Table 9. Statistical comparison of observed and downscaled mean monthly $T_{M a x}, T_{M i n}$ and PCP during calibration (19701990).

\begin{tabular}{|c|c|c|c|c|c|c|c|c|c|}
\hline Model & Variable & Data type & $\mu\left({ }^{\circ} \mathrm{C}\right)$ & $\mathrm{SD}\left({ }^{\circ} \mathrm{C}\right)$ & $\mathrm{SE}_{-} \mu\left({ }^{\circ} \mathrm{C}\right)$ & $\operatorname{MAD}\left({ }^{\circ} \mathrm{C}\right)$ & $\mathrm{R}^{2}$ & $\operatorname{RMSE}\left({ }^{\circ} \mathrm{C}\right)$ & MAPE \\
\hline \multirow{6}{*}{ CGCM3 } & \multirow[t]{2}{*}{$T_{\text {Max }}$} & $\mathrm{OBS}$ & 28.18 & 6.18 & 0.38 & 5.29 & - & - & - \\
\hline & & NCEP & 28.40 & 5.95 & 0.37 & 5.18 & 0.83 & 2.39 & 7.00 \\
\hline & \multirow[t]{2}{*}{$T_{\mathrm{Min}}$} & OBS & 14.48 & 6.73 & 0.42 & 6.19 & - & - & - \\
\hline & & NCEP & 14.49 & 6.66 & 0.42 & 6.16 & 0.91 & 1.93 & 10.04 \\
\hline & \multirow[t]{2}{*}{$\mathrm{PCP}(\mathrm{mm})$} & OBS & 87.60 & 98.30 & 6.20 & 73.4 & - & - & - \\
\hline & & NCEP & 86.30 & 90.20 & 5.70 & 68.0 & 0.50 & 63.6 & 273.2 \\
\hline \multirow{6}{*}{ HadCM3 } & \multirow[t]{2}{*}{$T_{\text {Max }}$} & OBS & 28.18 & 6.18 & 0.38 & 5.29 & - & - & - \\
\hline & & NCEP & 28.26 & 5.90 & 0.37 & 5.12 & 0.83 & 2.39 & 7.01 \\
\hline & \multirow[t]{2}{*}{$T_{\mathrm{Min}}$} & OBS & 14.48 & 6.73 & 0.42 & 6.19 & - & - & - \\
\hline & & NCEP & 14.54 & 6.79 & 0.43 & 6.07 & 0.92 & 1.88 & 19.77 \\
\hline & \multirow[t]{2}{*}{$\mathrm{PCP}(\mathrm{mm})$} & OBS & 87.57 & 98.19 & 6.20 & 73.41 & - & - & - \\
\hline & & NCEP & 86.70 & 93.57 & 5.91 & 70.47 & 0.42 & 68.34 & 304.33 \\
\hline
\end{tabular}

Table 10. Statistical comparison of observed and downscaled mean monthly $T_{M a x}, T_{M i n}$ and PCP during validation (19912000).

\begin{tabular}{|c|c|c|c|c|c|c|c|c|c|}
\hline Model & Variable & Data type & $\mu\left({ }^{\circ} \mathrm{C}\right)$ & $\mathrm{SD}\left({ }^{\circ} \mathrm{C}\right)$ & $\mathrm{SE}_{-} \mu\left({ }^{\circ} \mathrm{C}\right)$ & $\operatorname{MAD}\left({ }^{\circ} \mathrm{C}\right)$ & $\mathrm{R}^{2}$ & $\mathrm{RMSE}\left({ }^{\circ} \mathrm{C}\right)$ & MAPE \\
\hline \multirow{9}{*}{ CGCM3 } & \multirow[t]{3}{*}{$\left(T_{\operatorname{Max}}\right.$} & OBS & 28.02 & 6.31 & 0.57 & 5.42 & - & - & - \\
\hline & & NCEP & 28.31 & 5.66 & 0.51 & 4.91 & 0.80 & 2.53 & 7.20 \\
\hline & & 20C3M & 28.28 & 6.13 & 0.55 & 5.35 & 0.80 & 2.63 & 5.88 \\
\hline & \multirow[t]{3}{*}{$T_{\mathrm{Min}}$} & OBS & 13.71 & 7.01 & 0.64 & 6.26 & - & - & - \\
\hline & & NCEP & 14.69 & 6.57 & 0.60 & 5.89 & 0.88 & 2.07 & 4.88 \\
\hline & & 20C3M & 14.97 & 6.80 & 0.62 & 6.04 & 0.92 & 1.83 & 3.42 \\
\hline & \multirow[t]{3}{*}{$\mathrm{PCP}(\mathrm{mm})$} & OBS & 86.8 & 93.7 & 8.6 & 70.5 & - & - & - \\
\hline & & NCEP & 89.5 & 99.6 & 9.1 & 76.6 & 0.4 & 76.3 & 327.0 \\
\hline & & 20C3M & 84.3 & 86.7 & 7.9 & 66.5 & 0.4 & 65.7 & 256.7 \\
\hline \multirow{9}{*}{ HadCM3 } & \multirow[t]{3}{*}{$T_{\mathrm{Max}}$} & OBS & 28.02 & 6.31 & 0.57 & 5.42 & - & - & - \\
\hline & & NCEP & 28.46 & 5.80 & 0.47 & 4.98 & 0.81 & 2.49 & 6.98 \\
\hline & & 20C3M & 28.29 & 5.97 & 0.54 & 5.26 & 0.77 & 2.80 & 7.34 \\
\hline & \multirow[t]{3}{*}{$T_{\mathrm{Min}}$} & OBS & 13.71 & 7.01 & 0.64 & 6.26 & - & - & - \\
\hline & & NCEP & 14.70 & 6.86 & 0.62 & 6.10 & 0.89 & 2.14 & 15.50 \\
\hline & & 20C3M & 14.97 & 6.97 & 0.63 & 6.12 & 0.89 & 2.29 & 16.76 \\
\hline & \multirow[t]{3}{*}{$\mathrm{PCP}(\mathrm{mm})$} & OBS & 86.77 & 93.75 & 8.59 & 70.52 & - & - & - \\
\hline & & NCEP & 88.42 & 95.04 & 8.71 & 72.42 & 0.41 & 70.36 & 281.26 \\
\hline & & 20C3M & 89.80 & 101.76 & 9.33 & 72.18 & 0.41 & 74.09 & 252.16 \\
\hline
\end{tabular}

variables is found and this is known as bias. Salzmann et al. (2007) suggested eliminating biases from the daily time series of downscaled data. In this study, method discussed by Mahmood and Babel (2013) is applied for removing biases in the time series. First of all, biases are computed by subtracting (in case of temperature) or dividing (in case of precipitation) the long term monthly mean (30 years from 1971-2000) of observed data from the mean monthly simulated control data (downscaled data by SDSM for the period of 1971-2000 under 20C3M experiment). Then, biases are adjusted with the future downscaled daily time series according to their respective months. Equations (5 and 6) are used to de-bias daily temperature $\left(T_{\mathrm{Max}}\right.$ and $\left.T_{\mathrm{Min}}\right)$ and precipitation data.

$$
\begin{gathered}
T_{\mathrm{deb}}=T_{\mathrm{SCEN}}-\left(\bar{T}_{\mathrm{CONT}}-\bar{T}_{\mathrm{OBS}}\right) \\
P_{\mathrm{deb}}=P_{\mathrm{SCEN}} \times\left(\frac{\bar{P}_{\mathrm{OBS}}}{\bar{P}_{\mathrm{CONT}}}\right)
\end{gathered}
$$

where $T_{\text {deb }}$ and $P_{\text {deb }}$ are the de-biased (corrected) future daily time series of temperature and precipitation data, whereas $T_{\mathrm{SCEN}}$ and $P_{\mathrm{SCEN}}$ are biased (uncorrected) future daily time series of temperature and precipitation data downscaled by SDSM. $\bar{T}_{\mathrm{CONT}}, \bar{P}_{\mathrm{CONT}}$ and $\bar{T}_{\mathrm{OBS}}, \bar{P}_{\mathrm{OBS}}$ are long term mean 
monthly values of temperature and precipitation during control simulation (20C3M) and observed period, i.e., 1971-2000 respectively.

\subsection{Downscaling and projection of future changes} in temperature $\left(T_{M a x}\right.$ and $\left.T_{M i n}\right)$ and precipitation

The developed SDSM model is applied to downscale and generate future scenarios of daily temperature $\left(T_{\text {Max }}\right.$ and $\left.T_{\text {Min }}\right)$ and precipitation from predictors of CGCM3 (SRES A2 and A1B) and HadCM3 (SRES A2 and B2) models for the period of 2011-2099. Further, the future period is grouped into 2020s (2011-2040), 2050s (2041-2070) and 2080s (2071-2099) for studying pattern of change in temperature and precipitation with reference to base period (1971-2000). The baseline (1971-2000) corresponds to the observed data. The biases from daily time series of temperature and precipitation data are removed as discussed in section 3.4 before the analysis. For the analysis, daily values of temperature and precipitation are summed to obtain annual and monthly values at each station. Further, mean annual and monthly values of temperature and precipitation are attained from all the stations.

\subsubsection{Change in future annual and monthly temperature $\left(T_{\text {Max }}\right.$ and $\left.T_{\text {Min }}\right)$}

The change in mean annual $T_{\text {Max }}$ and $T_{\text {Min }}$ in Sutlej River Basin under scenarios A1B, A2 of CGCM3 model and A2, B2 of HadCM3 model is given in table 11 . The rise in $T_{\text {Max }}$ and $T_{\text {Min }}$ is predicted in future under all scenarios of both the models. In case of CGCM3 model for $T_{\mathrm{Max}}$, increase is $0.45^{\circ}$, $0.78^{\circ}$, and $0.82^{\circ} \mathrm{C}$ under $\mathrm{A} 1 \mathrm{~B}$ scenario and $0.66^{\circ}$, $0.81^{\circ}$ and $1.12^{\circ} \mathrm{C}$ under $\mathrm{A} 2$ scenario for future periods of 2020s, 2050s, 2080s respectively. For $T_{\mathrm{Min}}$ under scenarios $\mathrm{A} 1 \mathrm{~B}$ and $\mathrm{A} 2$, this is $1.08^{\circ}, 1.61^{\circ}$, $2.05^{\circ} \mathrm{C}$ and $1.13^{\circ}, 1.74^{\circ}, 2.66^{\circ} \mathrm{C}$ in $2020 \mathrm{~s}, 2050 \mathrm{~s}$ and 2080s respectively. Similarly for HadCM3 model, increase in $T_{\mathrm{Max}}$ under A2 scenario is $0.60^{\circ}, 1.06^{\circ}$, $1.82^{\circ} \mathrm{C}$ and under $\mathrm{B} 2$ scenario is $0.58^{\circ}, 0.76^{\circ}$, $1.25^{\circ} \mathrm{C}$ for all three future periods. For $T_{\text {Min }}$ under scenarios $\mathrm{A} 2$ and $\mathrm{B} 2$, it is $1.18^{\circ}, 2.24^{\circ}, 3.43^{\circ} \mathrm{C}$ and $1.18^{\circ}, 1.87^{\circ}, 2.52^{\circ} \mathrm{C}$ in $2020 \mathrm{~s}, 2050 \mathrm{~s}$ and $2080 \mathrm{~s}$ respectively. The projected increment is high for A2 scenario because it has the highest concentration of carbon dioxide $\left(\mathrm{CO}_{2}\right)$, i.e., $850 \mathrm{ppm}$ and it is followed by A1B (720 ppm) and B2 (450 ppm) scenarios respectively.

The change of pattern in mean monthly $T_{\mathrm{Max}}$ and $T_{\mathrm{Min}}$ under scenarios $\mathrm{A} 1 \mathrm{~B}$ and $\mathrm{A} 2$ of CGCM3 model with respect to base period for all three future periods is shown in figure 3 . The significant increase in mean monthly $T_{\text {Max }}$ is predicted from January to May and from September to December under $\mathrm{A} 1 \mathrm{~B}$ and $\mathrm{A} 2$ scenarios. It is in the range of $0.02^{\circ}-1.63^{\circ} \mathrm{C}, 0.68^{\circ}-1.69^{\circ} \mathrm{C}, 1.20^{\circ}-2.46^{\circ} \mathrm{C}$ under A1B scenario and $0.05^{\circ}-2.10^{\circ}, 0.44^{\circ}-2.26^{\circ}, 1.41^{\circ}-$ $3^{\circ} \mathrm{C}$ under A2 scenario in 2020s, 2050s and 2080s respectively. The highest increase in $T_{\text {Max }}\left(3^{\circ} \mathrm{C}\right)$ is anticipated in the month of March under A2 scenarios in 2080s. On the contrary, substantial decrease in $T_{\mathrm{Max}}$ is predicted in months of June, July and August under both the scenarios for future periods whereas highest decrease can be seen in the month of July. In case of $T_{\text {Min }}$, increase is observed throughout year under scenarios $\mathrm{A} 1 \mathrm{~B}$ and $\mathrm{A} 2$ of CGCM3 model for all three future periods and it is more prominent in the month of October. The predicted increase in monthly $T_{\mathrm{Min}}$ is in range of $0.10^{\circ}-$ $2.48^{\circ} \mathrm{C}, 0.29^{\circ}-3.05^{\circ} \mathrm{C}, 0.49^{\circ}-4.38^{\circ} \mathrm{C}$ under $\mathrm{A} 1 \mathrm{~B}$ scenario and $0.06^{\circ}-2.39^{\circ} \mathrm{C}, 0.42^{\circ}-3.76^{\circ} \mathrm{C}, 0.75^{\circ}-$ $5.10^{\circ} \mathrm{C}$ under A2 scenario in $2020 \mathrm{~s}, 2050 \mathrm{~s}$ and $2080 \mathrm{~s}$ respectively.

Similarly, projected change in mean monthly $T_{\mathrm{Max}}$ and $T_{\mathrm{Min}}$ for future periods under $\mathrm{A} 2$ and B2 scenarios of HadCM3 model is shown in figure 4 . The overall rise in mean monthly $T_{\mathrm{Max}}$

Table 11. Mean annual change in $T_{\text {Max }}, T_{\text {Min }}$ and PCP under different emission scenarios in 2020s, 2050s and 2080s.

\begin{tabular}{|c|c|c|c|c|c|}
\hline Model & $\begin{array}{l}\text { Future time } \\
\text { period }\end{array}$ & Scenario & $\begin{array}{l}\text { Change in } \\
T_{\operatorname{Max}}\left({ }^{\circ} \mathrm{C}\right)\end{array}$ & $\begin{array}{l}\text { Change in } \\
T_{\text {Min }}\left({ }^{\circ} \mathrm{C}\right)\end{array}$ & $\begin{array}{l}\text { Change in } \\
\text { PCP }(\mathrm{cm})\end{array}$ \\
\hline \multirow{6}{*}{ CGCM3 } & \multirow[t]{2}{*}{$\int 2020 \mathrm{~s}$} & A1B & 0.45 & 1.08 & 25.09 \\
\hline & & $\mathrm{A} 2$ & 0.66 & 1.13 & 21.79 \\
\hline & \multirow[t]{2}{*}{$2050 \mathrm{~s}$} & $\mathrm{~A} 1 \mathrm{~B}$ & 0.78 & 1.61 & 50.22 \\
\hline & & $\mathrm{A} 2$ & 0.81 & 1.74 & 45.0 \\
\hline & \multirow[t]{2}{*}{$2080 \mathrm{~s}$} & $\mathrm{~A} 1 \mathrm{~B}$ & 0.82 & 2.05 & 58.40 \\
\hline & & $\mathrm{A} 2$ & 1.12 & 2.66 & 88.48 \\
\hline \multirow{6}{*}{ HadCM3 } & \multirow[t]{2}{*}{$2020 \mathrm{~s}$} & $\mathrm{~A} 2$ & 0.60 & 1.18 & 9.29 \\
\hline & & B2 & 0.58 & 1.18 & 8.34 \\
\hline & \multirow[t]{2}{*}{$2050 \mathrm{~s}$} & $\mathrm{~A} 2$ & 1.06 & 2.24 & 45.10 \\
\hline & & B2 & 0.76 & 1.87 & 32.27 \\
\hline & \multirow[t]{2}{*}{$2080 \mathrm{~s}$} & $\mathrm{~A} 2$ & 1.82 & 3.43 & 87.38 \\
\hline & & B2 & 1.25 & 2.52 & 24.38 \\
\hline
\end{tabular}



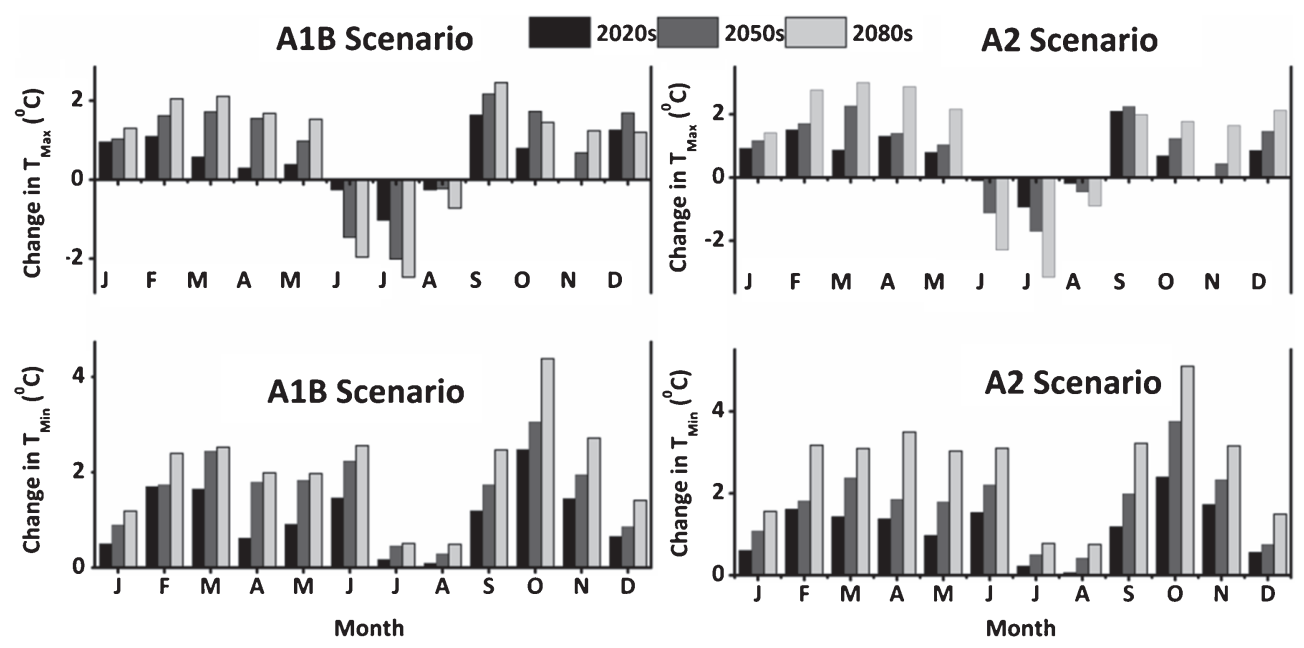

Figure 3. Mean monthly change in projected $T_{\mathrm{Max}}$ and $T_{\mathrm{Min}}$ under A1B and A2 scenarios of CGCM3 model.
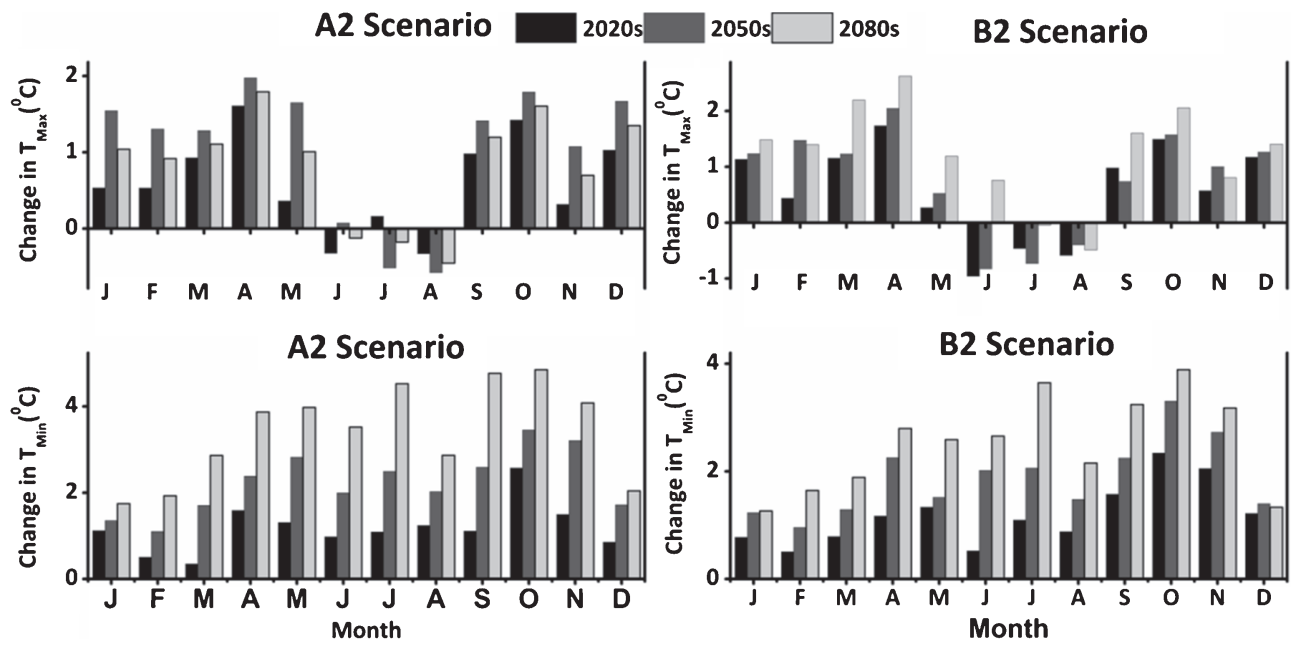

Figure 4. Mean monthly change in projected $T_{\mathrm{Max}}$ and $T_{\mathrm{Min}}$ under A2 and B2 scenarios of HadCM3 model.

is predicted from January to May and from September to December whereas decline in months of June, July and August under scenarios A2 and B2 in 2020s, 2050s and 2080s. The increase in $T_{\text {Max }}$ is in range of $0.16^{\circ}-1.61^{\circ} \mathrm{C}, 0.07^{\circ}-1.98^{\circ} \mathrm{C}, 0.70^{\circ}-$ $1.79^{\circ} \mathrm{C}$ under $\mathrm{A} 2$ scenario and $0.27^{\circ}-1.74^{\circ} \mathrm{C}, 0.74^{\circ}-$ $2.05^{\circ} \mathrm{C}, 0.76^{\circ}-2.62^{\circ} \mathrm{C}$ under $\mathrm{B} 2$ scenario, respectively. The highest increase and decrease in $T_{\text {Max }}$ is expected in months of April and June respectively. The increase observed in mean monthly $T_{\text {Min }}$ is in accordance with the results obtained from CGCM3 model. This is found in range of $0.35^{\circ}-2.58^{\circ} \mathrm{C}$, $1.10^{\circ}-3.45^{\circ} \mathrm{C}, 1.74^{\circ}-4.85^{\circ} \mathrm{C}$ under $\mathrm{A} 2$ scenario and $0.15^{\circ}-2.34^{\circ} \mathrm{C}, 0.96^{\circ}-3.30^{\circ} \mathrm{C}, 2.6^{\circ}-3.89^{\circ} \mathrm{C}$ under $\mathrm{B} 2$ scenario, respectively.

\subsubsection{Change in future annual and monthly precipitation}

The analysis of downscaled precipitation predicts rise in mean annual precipitation in Sutlej Basin for the future periods (2020s, 2050s and 2080s) under all scenarios of both the models (table 11). This increase in precipitation may be attributed to an increase in the surface temperature which in turn may raise rate of evaporation leading to increased precipitation (Anandhi et al. 2008). The increase in mean annual precipitation (with respect to base period) is expected in range of $24.0 \%-55.4 \%$ under A1B scenario and $20.8 \%-84.5 \%$ under A2 scenario of CGCM3 model. For A1B and A2 scenarios, the maximum $(55.4 \%$ and $84.5 \%)$ and minimum $(24.0 \%$ and $20.8 \%)$ increase in mean annual precipitation is observed during 2020s and 2080s respectively. Similarly for HadCM3 model, the increase is observed in range of $8.9-83.4 \%$ and $8.0-30.8 \%$ under A2 and B2 scenarios. Under both the models, maximum increase in mean annual precipitation is reported for A2 scenario during 2020s, 2050s and 2080s.

Further, pattern of change in future mean monthly precipitation is shown in figure 5 for CGCM3 

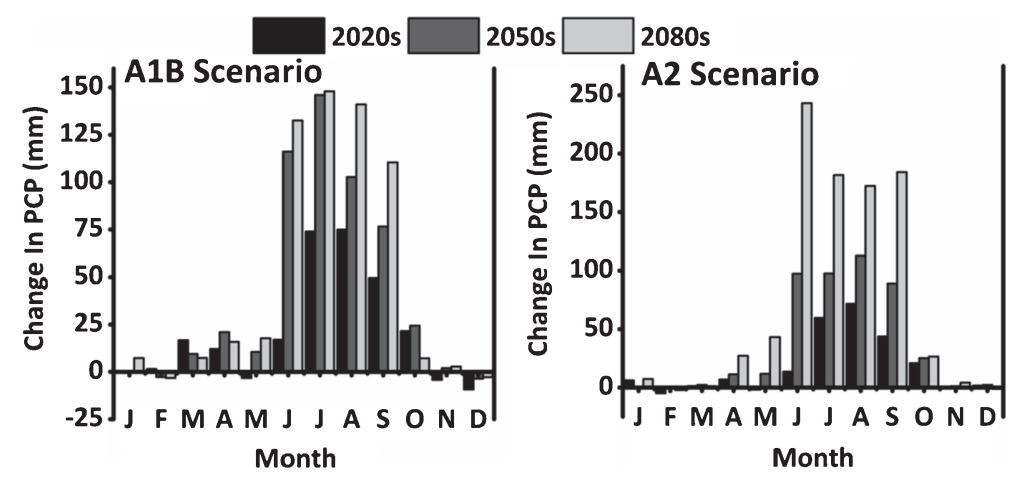

Figure 5. Mean monthly change in projected precipitation under A1B and A2 scenario of CGCM3 model.

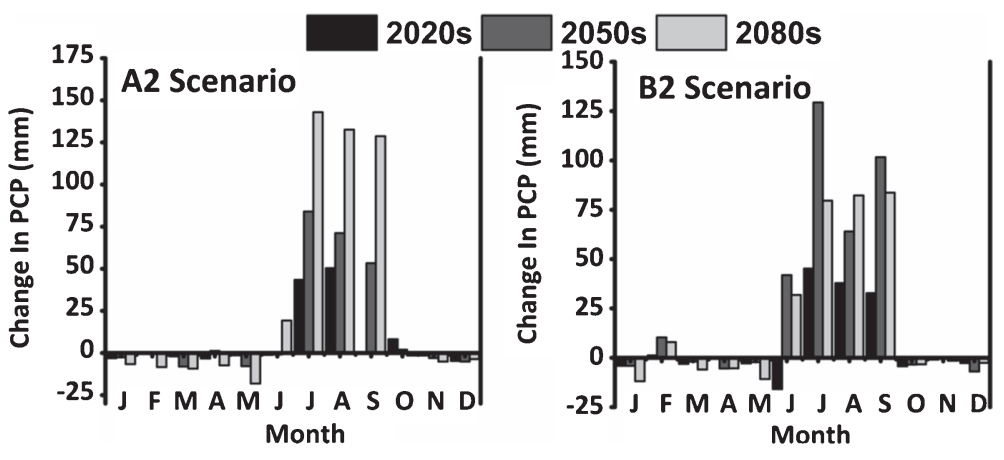

Figure 6. Mean monthly change in projected precipitation under A2 and B2 scenarios of HadCM3 model.

model under A1B and A2 scenarios. In this case, significant increase in precipitation with varying amount is projected in the months of April (1.2$2.1 \mathrm{~cm}$ under A1B and 0.6-2.7 $\mathrm{cm}$ under A2), June (1.7-13.2 $\mathrm{cm}$ under $\mathrm{A} 1 \mathrm{~B}$ and $1.3-23.3 \mathrm{~cm}$ under A2), July (7.3-14.7 cm under A1B and 5.1-18.1 cm under A2), August (7.4-14.1 cm under A1B and 7.1-17.2 cm under A2), September $(4.9-11.0 \mathrm{~cm}$ under A1B and $4.3-18.4 \mathrm{~cm}$ under $\mathrm{A} 2)$ and October $(0.7-2.4 \mathrm{~cm}$ under $\mathrm{A} 1 \mathrm{~B}$ and $2.0-2.6 \mathrm{~cm}$ under A2) during 2020s, 2050s and 2080s respectively. Besides, a slight increase in precipitation under $\mathrm{A} 1 \mathrm{~B}$ and $\mathrm{A} 2$ scenarios is also observed in months January and March during 2020s, 2050s and 2080s followed by May and November during 2050 s and 2080s. However, slight decrease $(<1.0$ $\mathrm{cm})$ in precipitation is recorded during future periods in February under A1B and A2 scenarios and in December under A1B scenario respectively.

The results derived under A2 and B2 scenarios of HadCM3 model are shown in figure 6 which shows large variability in pattern of monthly future precipitation. A small decrease $(\leq 0.1 \mathrm{~cm})$ in precipitation is observed during A2 and B2 scenarios in months of January, March, November and December followed by considerable rise in July (4.3-14.2 $\mathrm{cm}$ under A2 and 4.5-12.9 cm under B2), August (3.7-8.2 cm under A2 and 3.7-8.2 cm under B2) and September (0.04-12.8 cm under A2 and 3.2$10.1 \mathrm{~cm}$ under B2) during 2020s, 2050s and 2080s.
The increase observed in projected precipitation during monsoon season (June, July, August and September) under both the models could be the result of the projected intensification of the heat low over NW India, the trough of low pressure over the Indo-Gangetic plains, and the land-ocean pressure gradient during the establishment phase of the monsoon (Kripalani et al. 2007b). Besides, small increase in 2020s and 2050s is observed in precipitation followed by decrease in 2080s under A2 scenario in months of February and October. However, under B2 scenario increase in precipitation is observed in February during 2020s, 2050s and 2080s followed by decrease in May and October respectively.

\subsection{Comparison between downscaled temperature $\left(T_{M a x}\right.$ and $\left.T_{M i n}\right)$ and precipitation of CGCM3 and HadCM3 models under A2 scenario}

The results of downscaled mean annual $T_{\text {Max }}, T_{\text {Min }}$, and precipitation show substantial rise in future under A2 scenario for both CGCM3 and HadCM3 models. However, rise in annual $T_{\mathrm{Max}}$ and $T_{\mathrm{Min}}$ is much higher for HadCM3 model compared to CGCM3 model. The increase in annual $T_{\text {Max }}$ and $T_{\text {Min }}$ for HadCM3 model is $0.60^{\circ}, 1.06^{\circ}, 1.82^{\circ} \mathrm{C}$ and $1.18^{\circ}, 2.24^{\circ}, 3.43^{\circ} \mathrm{C}$ whereas for CGCM3 model increase is $0.66^{\circ}, 0.81^{\circ}, 1.12^{\circ} \mathrm{C}$ and $1.13^{\circ}, 1.74^{\circ}$, $2.66^{\circ} \mathrm{C}$ in $2020 \mathrm{~s}, 2050 \mathrm{~s}$ and $2080 \mathrm{~s}$, respectively. 

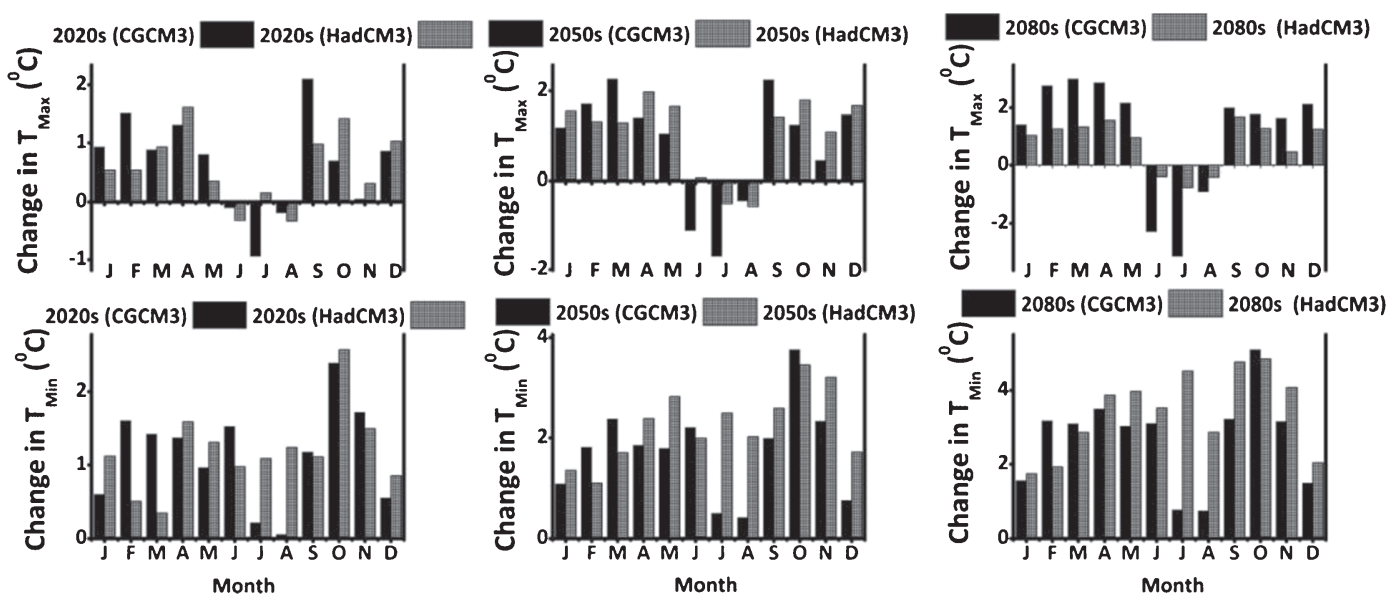

Figure 7. Comparison between projected $T_{\mathrm{Max}}$ and $T_{\mathrm{Min}}$ of CGCM3 and HadCM3 models under A2 scenario.
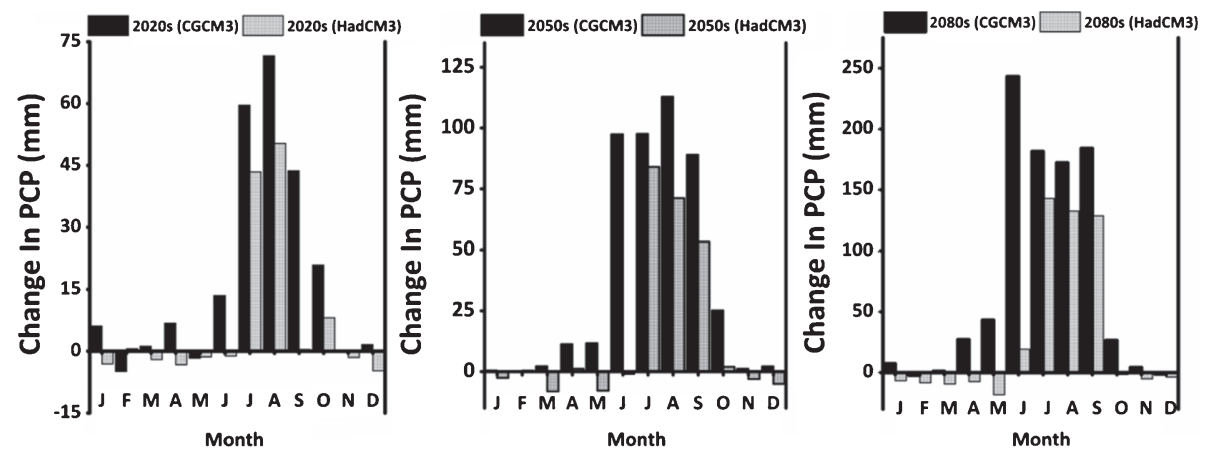

Figure 8. Comparison between projected precipitation of CGCM3 and HadCM3 models under A2 scenario.

For precipitation, more or less similar pattern of increase is observed under both the models in 2020s, 2050s and 2080s, respectively. The increase in annual precipitation is observed as $21.7,45$ and $88.4 \mathrm{~cm}$ for CGCM3 model and 9.2, 45.1 and 87.3 cm for HadCM3 model for 2020s, 2050s and 2080s, respectively.

Figure 7 shows projected mean monthly changes in temperature ( $T_{\mathrm{Max}}$ and $\left.T_{\mathrm{Min}}\right)$ under $\mathrm{A} 2$ scenario for both the models. Generally, similar patterns of change in monthly $T_{\mathrm{Max}}$ and $T_{\mathrm{Min}}$ are observed in 2020s, 2050s and 2080s for CGCM3 and HadCM3 models but deviation of amount is noticed between them. Both the models predict increase in future $T_{\text {Min }}$ from January to December. In case of CGCM3 model, the predicted increase is in the range of $0.06^{\circ}-2.39^{\circ} \mathrm{C}, 0.42^{\circ}-3.76^{\circ} \mathrm{C}, 0.75^{\circ}-5.10^{\circ} \mathrm{C}$ during 2020s, 2050s and 2080s, respectively. The minimum increase in $T_{\mathrm{Min}}$ (CGCM3) is observed in month of August whereas the maximum increase is in the month of October. Similarly for HadCM3 model, the increase predicted is in the range of $0.35^{\circ}-$ $2.58^{\circ} \mathrm{C}, 1.10-3.45^{\circ} \mathrm{C}$ and $1.74^{\circ}-4.85^{\circ} \mathrm{C}$ in future periods (2020s, 2050s and 2080s), respectively. The minimum increase in $T_{\text {Min }}$ (HadCM3) is observed in the months of March (2020s), February (2050s), January (2080s) and maximum in the month of October. Generally, increase in $T_{\text {Max }}$ is observed from January to May and September to December whereas decrease in months of June, July and August under both the models. The decrease in $T_{\mathrm{Max}}$ is more significant under A2 scenario of CGCM3 model compared to HadCM3 model. The decrease in $T_{\text {Max }}$ (CGCM3) in months of June, July and August is observed in the range of $0.10^{\circ}-$ $0.94^{\circ} \mathrm{C}, 0.45^{\circ}-1.70^{\circ} \mathrm{C}$ and $0.89^{\circ}-3.15^{\circ} \mathrm{C}$ in $2020 \mathrm{~s}$, $2050 \mathrm{~s}$ and $2080 \mathrm{~s}$, respectively. The increase in $T_{\mathrm{Max}}$ instead of decrease is noticed in months of June (2050s) and July (2020s) under A2 scenario of HadCM3 model.

Figure 8 shows projected mean monthly changes in precipitation under A2 scenario for both the models. The pattern in future monthly precipitation observed under A2 scenario of CGCM3 model significantly differs from the HadCM3 model. However, similarity in pattern is detected in months of July, August, September and October when both the models show considerable increase in precipitation for the future periods. The increase is the maximum for CGCM3 model as compared 
to HadCM3 model. This is projected in range of $5.9-18.1 \mathrm{~cm}$ in July, $7.1-17.2 \mathrm{~cm}$ in August, 4.3$18.4 \mathrm{~cm}$ in September and 2.0-2.6 cm in October for CGCM3 model during 2020s, 2050s and 2080s, respectively. Besides, slight increase in precipitation is also observed for CGCM3 model contrary to HadCM3 model in the months of January, March and December for the future periods.

\section{Conclusion}

SDSM (hybrid of MLR and SWG based downscaling technique) is used to downscale and generate long-term (2011-2040, 2041-2070 and 2071-2099) future scenarios of climate variables (temperature and precipitation) from predictors of CGCM3 and HadCM3 models in the middle catchment of Sutlej River Basin, India. These future scenarios are generated under forcings of $\mathrm{A} 2, \mathrm{~A} 1 \mathrm{~B}$ and B2 emission scenarios. The monthly submodel of SDSM is found proficient in downscaling of maximum and minimum temperature as high correlation $\left(R^{2}>0.80\right.$ for $T_{\text {Max }}$ and $R^{2}>0.90$ for $T_{\text {Min }}$ for calibration periods and $R^{2}>0.77$ for $T_{\text {Max }}$ and $R^{2}>0.89$ for $T_{\text {Min }}$ for validation period) are obtained between downscaled and observed data. The climate of 20th century was well simulated by SDSM because the different statistical measures computed for 20C3M scenario during validation period show close agreement with the statistics of observed data. However, comparatively lower values $\left(R^{2}<0.50\right)$ are observed in case of precipitation. This may be due to limitations of CGCM3 and HadCM3 models in capturing monsoonal phenomenon resulting in poor simulations of predictors during this phase of year. Besides, precipitation is an intermediate process and conditioned by local weather conditions. This indicates complexities involved in downscaling of precipitation.

SDSM projects increase in mean annual temperature and precipitation for the future periods (2020s, 2050s and 2080s) under both the models for all the emission scenarios. The projected increase for $T_{\text {Max }}$ varies from $0.45^{\circ}-0.82^{\circ} \mathrm{C}$ and $0.66^{\circ}-1.12^{\circ} \mathrm{C}$ under $\mathrm{A} 1 \mathrm{~B}$ and $\mathrm{A} 2$ scenarios of $\mathrm{CGCM} 3$ model while for $T_{\text {Min }}$ it ranges from $1.08^{\circ}$ to $2.05^{\circ} \mathrm{C}$ (A1B scenario) and $1.13^{\circ}-2.66^{\circ} \mathrm{C}$ (A2 scenario) respectively. In case of HadCM3 model, increase in $T_{\text {Max }}$ under A2 scenario is projected to vary from $0.60^{\circ}$ to $1.82^{\circ} \mathrm{C}$ and under $\mathrm{B} 2$ scenario from $0.58^{\circ}$ to $1.25^{\circ} \mathrm{C}$ respectively. For $T_{\text {Min }}$ under scenarios $\mathrm{A} 2$ and $\mathrm{B} 2$, it varies from $1.18^{\circ}$ to $3.43^{\circ} \mathrm{C}$ and $1.18^{\circ}$ to $2.52^{\circ} \mathrm{C}$ in $2020 \mathrm{~s}, 2050 \mathrm{~s}$ and $2080 \mathrm{~s}$, respectively. The increase projected in temperature and precipitation in the present study is more or less similar in patterns to the projected increase in the surrounding basins. The study of Mahmood and Babel (2013) conducted over Jhelum Basin (Pakistan-India) in NW Himalaya predicted significant rise in mean annual $T_{\text {Max }}\left(0.91^{\circ}-3.15^{\circ} \mathrm{C}\right.$ under $\mathrm{A} 2$ and $0.69^{\circ}-1.92^{\circ} \mathrm{C}$ under B2 scenarios), $T_{\text {Min }}\left(0.93^{\circ}-2.63^{\circ} \mathrm{C}\right.$ under $\mathrm{A} 2$ and $0.56^{\circ}-1.63^{\circ} \mathrm{C}$ under B2 scenarios) and precipitation (6\%-12\% and $8 \%-14 \%$ under A2 and B2 respectively) for 2020s, 2050s and 2080s. Similarly, the study undertaken by Srinivas et al. (2013) over Beas Basin predicted increase in amount of $T_{\text {Max }}$ and $T_{\text {Min }}$ under A1B, A2 and B1 scenarios of CGCM3 model.

The rise in mean annual $T_{\text {Min }}$ is more when compared to $T_{\mathrm{Max}}$ in the study area. The projected increment is higher under scenarios of HadCM3 model as compared to CGCM3 model. However, contrary to this, relatively higher increase in mean annual precipitation is observed for CGCM3 model as compared to HadCM3 model. The projected mean monthly $T_{\text {Max }}$ shows increase during January-May and September-December whereas decrease is observed in the months of June, July and August under all scenarios of both the models. The increase in mean monthly $T_{\text {Min }}$ is predicted throughout the year. The comparison of results explains that the changes in $T_{\mathrm{Max}}$ and $T_{\mathrm{Min}}$ predicted under various forcings of two GCMs used are different in magnitude but similar in their patterns. However, results derived from CGCM3 model are slightly better as compared to HadCM3 model. This may be attributed to the fact that higher value of $R^{2}$ is obtained for $T_{\text {Max }}$ and $T_{\text {Min }}$ under 20C3M scenario of CGCM3 model (0.80 and 0.92) as compared to HadCM3 model (0.77 and 0.89). Significant variations in monthly pattern of future precipitation are observed under different scenarios of both the models. However, similarity is observed in months of July, August and September where both the models under all scenarios show increase in precipitation with varying amount for the future periods.

The future patterns of change in $T_{\text {Max }}, T_{\text {Min }}$ and precipitation discussed in this study are based on plausible scenarios. The large uncertainties are coupled with the quantitative estimates because the projected temperature inherited uncertainties due to uncertainties associated with CGCM3 and HadCM3 models and limitations of the SDSM in downscaling of temperature. However, downscaled $T_{\text {Max }}$ and $T_{\text {Min }}(20 \mathrm{C} 3 \mathrm{M})$ from predictors of CGCM3 and HadCM3 models have shown quite good statistical agreement with observed $T_{\text {Max }}$ and $T_{\text {Min }}$ due to higher correlation found between observed and downscaled $T_{\text {Max }}$ and $T_{\text {Min }}$. Thus, it can be concluded that SDSM has performed well in downscaling of $T_{\text {Max }}$ and $T_{\text {Min }}$ from predictors of CGCM3 and HadCM3 models in a mountainous river basin, India. 


\section{Acknowledgements}

Authors acknowledge the financial support in the form of fellowship provided by University Grants Commission (UGC), Government of India to Mr. Dharmaveer Singh as Research Fellow for carrying out this research. Authors are also thankful to Bhakara Beas Management Board (BBMB), India for providing the meteorological data used in the present work. Authors thank Dr R L Wilby (Professor, Department of Geography, Loughborough University, UK) for his valuable suggestions with regard to SDSM. Authors also acknowledge anonymous reviewers for their constructive comments and suggestions to improve the quality of the manuscript.

\section{References}

Aherne J, Futter M N and Dillion P J 2008 The impacts of future climate change and sulphur emission reductions on acidification recovery at Plastic Lake, Ontario; Hydrol. Earth Syst. Sci. 12(2) 383-392.

Anandhi A, Shrinivas V V, Nanjundiah R S and Kumar D N 2008 Downscaling precipitation to river basin in India for IPCC SRES scenarios using support vector machine; Int. J. Climatol. 28(3) 401-420, doi: 10.1002/joc.1529.

Anandhi A, Shrinivas V V, Nanjundiah R S and Kumar D N 2009 Role of predictors in downscaling surface temperature to river basin in India for IPCC SRES scenarios using support vector machine; Int. J. Climatol. 29(4) 583-603.

Basistha A, Arya D S and Goyal N K 2009 Analysis of historical changes in rainfall in the Indian Himalayas; Int. J. Climatol. 29(4) 555-572, doi: 10.1002/joc.1706.

Bhutiyani M R, Kale V S and Pawar N J 2007 Longterm trends in maximum, minimum and mean annual air temperatures across the northwestern Himalaya during the twentieth century; Climatic Change 85 159-177, doi: 10.1007/s10584-006-9196-1.

Bhutiyani M R, Kale V S and Pawar N J 2008 Changing stream flow patterns in the rivers of northwestern Himalaya: Implications of global warming in the 20th century; Curr. Sci. 95(5) 618-624.

Bhutiyani M R, Kale V S and Pawar N J 2009 Climate change and the precipitation variations in the northwestern Himalaya: 1866-2006; Int. J. Climatol., doi: 10.1002/joc. 1920 .

Canadian Climate Impacts Scenarios (CCIS) available at http://www.cics.uvic.ca/scenarios/index.cgi.

Christensen J H, Machenhauer B, Jones R G, Schär C, Ruti P M, Castro M and Visconti G 1997 Validation of presentday regional climate simulations over Europe: LAM simulations with observed boundary conditions; Clim. Dyn. 13 489-506.

Combalicer E A, Cruz R V O, Lee S and Im S 2010 Assessing climate change impacts on water balance in the Mount Makiling forest, Philippines; J. Earth Syst. Sci. 119(3) 265-283.

Dai A 2006 Precipitation characteristics in eighteen coupled climate models; J. Climate 19(18) 4605-4630, doi: $10.1175 /$ JCLI3884.1.

Data access integration portal available at http://loki.qc.ec. gc.ca/DAI/predictors-e.html.
Dibike Y B and Coulibaly P 2005 Hydrologic impact of climate change in the Saguenay watershed: Comparison of downscaling methods and hydrologic models; J. Hydrol. 307 145-163.

Easterling D R 1999 Development of regional climate scenarios using a downscaling approach; Climate Change $\mathbf{4 1}$ 615-634.

Fowler H J, Blenkinsop S and Tebaldi C 2007 Linking climate change modelling to impacts studies: Recent advances in downscaling techniques for hydrological modelling; Int. J. Climatol. 27(12) 1547-1578.

Gagnon S, Singh B, Roussselle J and Roy L 2005 An application of the statistical downscaling model (SDSM) to simulate climatic data for stream flow modelling in Québec; Can. Water. Resour. J. 30(4) 297-314.

Ghosh S and Mishra C 2010 Assessing hydrological impacts of climate change: Modeling techniques and challenges; The Open Hydrology J. 4 115-121.

Giorgi F 1990 Simulation of regional climate using a limited area model nested in a general circulation model; J. Climate 3(9) 941-963.

Goswami A 2007 Spatial techniques in snow cover and snowmelt runoff studies in Western Himalaya; Unpublished thesis, Department of Earth Science, Indian Institute of Technology, Roorkee, India.

Goyal M K, Burn D H and Ojha C S P 2012 Statistical downscaling of temperatures under climate change scenarios for Thames river basin, Canada; Int. J. Global Warm. 4(1) 13-30.

Hashmi M Z, Shamseldin A Y and Melville B W 2011 Comparison of SDSM and LARS-WG for simulation and downscaling of extreme precipitation events in a watershed; Stoch. Env. Res. Risk A 25 475-484, doi: 10.1007/s00477-010-0416-x.

Hewitson B C and Crane R G 1996 Climate downscaling: Techniques and application; Clim. Res. 7(2) 85-95.

Huang J, Zhang J, Zhang Z, Xu C Y, Wang B and Yao J 2011 Estimation of future precipitation change in the Yangtze River basin by using statistical downscaling method; Stoch. Env. Res. Risk A 25(6) 781-792.

Jain S K, Goswami A and Saraf A K 2009 Assessment of snowmelt runoff using remote sensing and effect of climate change on runoff; Water Resour. Manag. 24 1763-1777.

Jones R G, Murphy J M and Noguer M 1995 Simulation of climate change over Europe using a nested regional climate model. I. Assessment of control climate, including sensitivity to location of lateral boundaries; Quart. J. Roy. Meteor. Soc. 121(526) 1413-1450, doi: 10.1002/qj.49712152610.

Kim J W, Chang J T, Baker N L, Wilks D S and Gates W L 1984 The statistical problem of climate inversion: Determination of the relationship between local and large-scale climate; Mon. Wea. Rev. 112 2069-2077.

Kripalani R H, Oh J H and Chaudhari H S 2007a Response of the East Asian summer monsoon to doubled atmospheric $\mathrm{CO}_{2}$ : Coupled climate model simulations and projections under IPCC AR4; Theor. Appl. Climatol. 87(1) 1-28, doi: 10.1007/s00704-006-0238-4.

Kripalani R H, Oh J H, Kulkarni A, Sabade S S and Chaudhari H S 2007b South Asian summer monsoon precipitation variability: Coupled climate model simulations and projections under IPCC AR4; Theor. Appl. Climatol. 90(3) 133-159, doi: 10.1007/s00704-006-0282-0.

Kulkarni A, Patwardhan S, Kumar K K, Ashok K and Krishnan R 2013 Projected climate change in the Hindu Kush-Himalayan region by using the high-resolution regional climate model PRECIS; Mt. Res. Dev. 33(2) 142-151, doi: 10.1659/MRD-JOURNAL-D-11-00131.1. 
Lapp S, Sauchyn D and Toth B 2009 Constructing scenarios of future climate and water supply for the SSRB: Use and limitations for vulnerability assessment; Prairie Forum (Guest Issue) 34(1) 153-180.

Mahmood R and Babel M S 2013 Evaluation of SDSM developed by annual and monthly sub-models for downscaling temperature and precipitation in the Jhelum Basin, Pakistan and India; Theor. Appl. Climatol. 113 27-44, doi: 10.1007/s00704-012-0765-0.

Marshall S J, Sharp M J, Burgess D O and Anslow F S 2007 Near-surface temperature lapse rates on the Prince of Wales Ice field, Ellesmere island, Canada: Implications for regional downscaling of temperature; Int. J. Climatol. 27(3) 385-398.

Masoud H, Philippe G, Taha B M J O and André S 2008 Automated regression-based statistical downscaling tool; Environ. Model. Softw. 23 813-834.

Meenu R, Rehana S and Mujumdar P P 2012 Assessment of hydrologic impacts of climate change in Tunga-Bhadra river basin, India with HEC-HMS and SDSM; Hydrol. Process., doi: 10.1002/hyp.9220.

Mutreja K N 1986 Applied Hydrology; Tata McGraw Hill Publishing Company Limited, New Delhi.

Rajeevan M and Nanjundiah R S 2009 Coupled model simulations of twentieth century climate of the Indian summer monsoon; Current Trends in Science, Indian Academy of Sciences, Bangalore, pp. 537-568.

Robinson P J and Finkelstein P L 1991 The development of impact-oriented climate scenarios; Bull. Am. Meteorol. Soc. 72 481-490.

Salzmann N, Frei C, Vidale P L and Hoelzle M 2007 The application of Regional Climate Model output for the simulation of high-mountain permafrost scenarios; Global Planet. Change 56(1-2) 188-202, doi: 10.1016/j.gloplacha.2006.07.006.

SANDRP (South Asian Network on Dam River and People) 2014 Hydro-electric projects in Sutlej River Basin; http://sandrp.in/basin_maps/Hydro_Electric_Projects_ on_Sutlej_River_in\%20HP.pdf.

Sarthi P P, Dash S K and Mamgain A 2012 Possible changes in the characteristics of Indian summer monsoon under warmer climate; Global Planet. Change 92-93 17-29, doi: 10.1016/ j.gloplacha.2012.03.006.

Srinivas V V, Basu B, Kumar N and Jain S K 2013 Multisite downscaling of maximum and minimum temperature using support vector machine; Int. J. Climatol., doi: doi/01002/joc.3782.

van der Made J W 1987 Casebook of methods for computing hydrological parameters for water projects; In: A contribution to the International Hydrological Programme (ed.) Lowing M J, UNESCO, Paris.

von Storch H, Langenber H and Feser F 2000 A spectral nudging technique for dynamical downscaling purposes; Mon. Wea. Rev. 128 3664-3673.

Wilby R L and Dawson C W 2007 SDSM user manual A decision support tool for the assessment of regional climate change impacts; https://copublic.lboro.ac.uk/ cocwd/SDSM/main.html.

Wilby R L and Dawson C W 2013 The statistical down scaling model: Insights from one decade of application; Int. J. Climatol. 33 1707-1719, doi: 10.1002/joc.3544.

Wilby R L and Wigley T M L 1997 Downscaling general circulation model output: A review of methods and limitations; Progr. Phys. Geogr. 21(4) 530-548.

Wilby R L, Dawson C W and Barrow E M 2002 SDSM A decision support tool for the assessment of regional climate change impacts; Environ. Model. Softw. 17 147-159.

Wilby R L, Hay L E, Gutowski W J, Arritt R W, Takle E S, Pan Z, Leavesley G H and Martyn P C 2000 Hydrological responses to dynamically and statistically downscaled climate model output; Geophys. Res. Lett. 27(8) 1199, doi: 10.1029/1999GL00607.

Xu Y C 1999 From GCMs to river flow: A review of downscaling methods and hydrologic modelling approaches; Progr. Phys. Geogr. 23(2) 229-249.

Yang W, Bárdossy A and Caspary H-J 2010 Downscaling daily precipitation time series using a combined circulation and regression based approach; Theor. Appl. Climatol. 102(3-4) 439-454, doi: 10.1007/s00704-010-0272-0.

Yarnal B, Comrie A C, Frakes B and Brown D P 2001 Developments and prospects in synoptic climatology; Int. J. Climatol. 21 1923-1950. 